\title{
Discovery and characterization of Isofistularin-3, a marine brominated alkaloid, as a new DNA demethylating agent inducing cell cycle arrest and sensitization to TRAIL in cancer cells
}

\author{
Cristina Florean ${ }^{1}$, Michael Schnekenburger ${ }^{1}$, Jin-Young Lee ${ }^{2}$, Kyung Rok Kim², \\ Aloran Mazumder ${ }^{2}$, Sungmi Song ${ }^{2}$, Jae-Myun Kim², Cindy Grandjenette ${ }^{1}$, Jeoung- \\ Gyun Kim ${ }^{3}$, Ah-Young Yoon ${ }^{3}$, Mario Dicato ${ }^{1}$, Kyu-Won Kim ${ }^{3}$, Christo Christov ${ }^{4}$, \\ Byung-Woo Han'2, Peter Proksch', Marc Diederich² \\ 1'Laboratoire de Biologie Moléculaire et Cellulaire du Cancer, Hôpital Kirchberg, Lëtzebuerg, Luxembourg \\ ${ }^{2}$ Department of Pharmacy, Research Institute of Pharmaceutical Sciences, College of Pharmacy, Seoul National University, \\ Gwanak-gu, Korea \\ ${ }^{3}$ SNU-Harvard Neurovascular Protection Center, College of Pharmacy and Research Institute of Pharmaceutical Sciences, \\ Seoul National University, Gwanak-gu, Korea \\ ${ }^{4}$ Faculté de Médecine, Université de Lorraine, Nancy, France \\ ${ }^{5}$ Institut für Pharmazeutische Biologie und Biotechnologie, Heinrich-Heine-Universität Düsseldorf, Düsseldorf, Germany \\ Correspondence to: Marc Diederich, e-mail: marcdiederich@snu.ac.kr
}

Keywords: leukemia, DNMT inhibitor, TSG hypermethylation, cell cycle arrest, autophagy

Received: September 01, 2015

Accepted: March 02, 2016

Published: March 19, 2016

\section{ABSTRACT}

We characterized the brominated alkaloid Isofistularin-3 (Iso-3), from the marine sponge Aplysina aerophoba, as a new DNA methyltransferase (DNMT)1 inhibitor. Docking analysis confirmed our in vitro DNMT inhibition data and revealed binding of Iso-3 within the DNA binding site of DNMT1. Subsequent increased expression of tumor suppressor gene aryl hydrocarbon receptor (AHR) could be correlated to decreased methylation of CpG sites within the essential Sp1 regulatory region of its promoter. Iso-3 induced growth arrest of cancer cells in G0/G1 concomitant with increased p21 and p27 expression and reduced cyclin E1, PCNA and c-myc levels. Reduced proliferation was accompanied by morphological changes typical of autophagy revealed by fluorescent and transmission electron microscopy and validated by LC3I-II conversion. Furthermore, Iso-3 strongly synergized with tumornecrosis-factor related apoptosis inducing ligand (TRAIL) in RAJI [combination index $(C I)=0.22]$ and $U-937$ cells $(C I=0.21)$ and increased TRAIL-induced apoptosis via a mechanism involving reduction of survivin expression but not of $\mathrm{Bcl}-2$ family proteins nor X-linked inhibitor of apoptosis protein (XIAP). Iso-3 treatment decreased FLIP $_{L}$ expression and triggered activation of endoplasmatic reticulum (ER) stress with increased GRP78 expression, eventually inducing TRAIL receptor death receptor (DR) 5 surface expression. Importantly, as a potential candidate for further anticancer drug development, Iso-3 reduced the viability, colony and in vivo tumor forming potential without affecting the viability of PBMCs from healthy donors or zebrafish development.

\section{INTRODUCTION}

Epigenetic mechanisms, including DNA methylation and histone modifications, play a central role in all physiological cellular functions, and their de-regulation is a well-established feature of cancer cells [1]. The possibility to revert tumor suppressor gene (TSG) hypermethylation, hence re-establishing TSG functions, represents a major perspective in anticancer therapy. Two demethylating agents, the nucleoside analogs 5-azacytidine and 5-aza-2'- 
deoxycytidine (DAC) have been approved for the treatment of myelodysplastic syndrome (MDS) [2-5]. However, their toxic effects in the clinical context triggered research of novel non-nucleoside molecules with demethylating activity and structurally different compounds have been reported so far to affect DNMT activity in vitro and TSG methylation in cell models [2, 6-8].

The chemical versatility of marine organisms has made them one of the most powerful sources of molecules for biomedical use. Marine sponges are a very rich source of natural secondary metabolites, many of which demonstrated interesting anticancer activities. Cytarabine (Ara-C) was the first sponge-derived compound to reach clinical use against leukemia, and constitutes now one of the standard treatments for hematological diseases [9-11].

Brominated compounds may present interesting epigenetic modulatory potential. The sponge-derived bromotyrosine derivative psammaplin-A (PsA, Figure 1A) and its derivatives were previously shown to inhibit both methyltransferase and histone deacetylase (HDAC) activities [12-16]. Isofistularin-3 (Iso-3, Figure 1A), a brominated alkaloid derived from Aplysina aerophoba, a marine sponge from the Mediterranean sea, was selected here due to its structural resemblance to PsA, being both bromotyrosine derivatives. No mechanistic study has been conducted so far to investigate the anticancer activity of this molecule. Nevertheless, cytotoxic activity against HeLa cells has been reported for Iso-3 [17], and a cytostatic effect was reported for Iso-3 structural isomer fistularin-3, against hematological cancer lines [18], indicating potential benefits in the use of Iso-3 against cancer.

As outcome of the induced gene expression modulation, epigenetic agents are known to produce a variety of cellular effects, ranging from cell cycle arrest and autophagy to cell death $[1,19,20]$. All these features contribute to the increasingly high interest raised by these molecules in anticancer research.

In this study, we describe Iso-3 as a new DNMT1 inhibitor with a strong impact on cancer cell proliferation, the induction of autophagy and a promising synergistic chemosensitizing activity to tumor-necrosis-factor related apoptosis inducing ligand (TRAIL) in combination treatments.

\section{RESULTS}

\section{Isofistularin-3 inhibits DNMT1 in vitro by binding to the DNA interacting pocket of the enzyme}

The ability of Iso-3 to reduce DNMT1 activity was determined by performing a molecular screening of a library of natural compounds, using a biochemical in vitro assay. Along with few other hits, (Supplementary Table S1 and Supplementary Figure S1A) we identified Iso-3 as a new DNMT1 inhibitor. The analysis revealed an inhibition of the purified enzyme by Iso- 3 with an $\mathrm{IC}_{50}$ of $13.5 \pm 5.4 \mu \mathrm{M}$. Green tea polyphenol EGCG was used as a positive control for in vitro DNMT1 inhibition. (Figure 1B). Addition of Triton X100 (0.01\%) [21] did not affect the inhibitory activity of Iso-3 (Supplementary Figure S2A), arguing against a potential aggregation-based inhibition. Increasing the concentration of the $S$-adenosyl methionine (SAM) cofactor did not affect Iso-3 activity, supporting a mechanism of DNMT1 inhibition that differs from competition with SAM (Figure 1C). Interestingly, the Iso-3 derivative bisoxazolidinone (Figure 1A), devoid of brominated side arms, failed to inhibit DNMT1 activity (Figure 1D).

In order to gain insight into the interaction modes of Iso-3 and human DNMT1, we implemented docking simulation using PatchDock software [22, 23]. In parallel, the Iso-3 structural analog aerothionin, presenting lower DNMT1 inhibitory activity (Supplementary Table S1) as well as the inactive analog bisoxasolidinone, were analyzed. Before assessing the affinity between compounds and DNMT1, we performed a control docking experiment with sinefungin to the crystal structure of DNMT1 (Protein Data Bank ID: 3SWR) after sinefungin was removed from the complex structure. Predicted binding score of Iso-3 was 7,426, whereas that of sinefungin was 5,372 from the control docking experiment (RMSD distance from sinefungin in the crystal structure of DNMT1-sinefungin complex: 1.292 Å). Predicted docking scores for aerothionin and bisoxasolidinone were 6,414 and 4,292, respectively (Figure 1E).

In the docking analyses, Iso-3 was predicted to be located in a DNA-binding CXXC domain with more stable energy score than that of sinefungin, whereas sinefungin is bound to SAM site of DNMT1. Iso-3 appeared to interact with positively charged residues, which might affect DNA binding activity. Electrostatic surface view of the crystal structure of DNMT1 suggests that electrostatic interaction is a major interacting force between Iso-3 and DNMT1. When the results were compared with the crystal structure of DNMT1-DNA complex (Protein Data Bank ID: 3PTA) [24], Iso-3 seemed to be located in the DNA binding site (Figure 1E). However, bisoxasolidinone was predicted to be located between CXXC domain and target recognition domain on DNMT1 and it may not interrupt binding of DNA or any other ligands with DNMT1. The binding score of bisoxasolidinone was lower than that of sinefungin. From our DNMT1 activity tests and docking studies, we hypothesize that Iso-3 could inhibit the interaction between DNMT1 and DNA.

\section{Isofistularin-3 modifies AHR promoter methylation and increases AHR expression in RAJI cells}

To ascertain that DNA methylation was affected by Iso-3, consistently with inhibition of DNMT1 activity, we investigated expression levels of the aryl hydrocarbon 
A

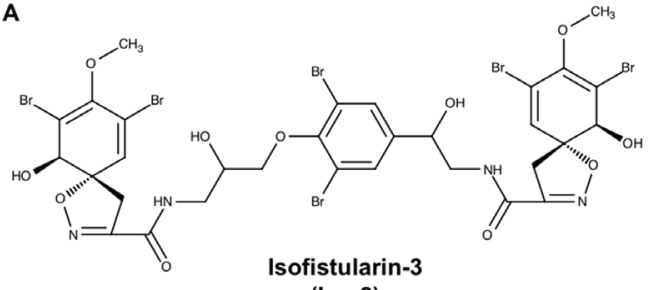
(Iso-3)<smiles>O=C1NCC(COc2c(Br)cc(C3CNC(=O)O3)cc2Br)O1</smiles><smiles>O=C(NCSSCNC(=O)/C(Cc1ccc(O)c(Br)c1)=N/O)/C(Cc1ccc(O)c(Br)c1)=N/O</smiles>

(PsA)

B

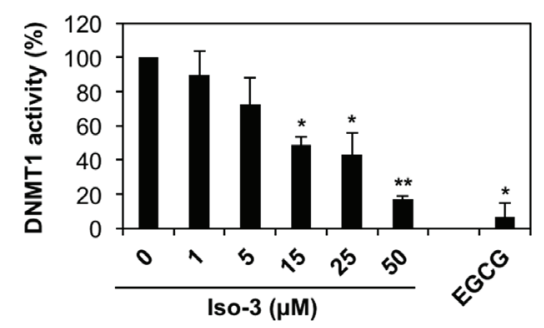

C

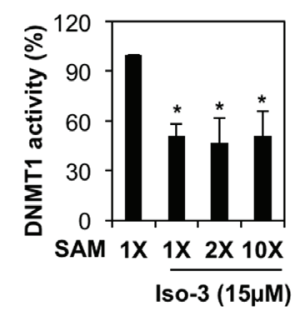

D

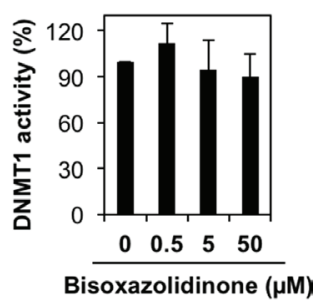

E
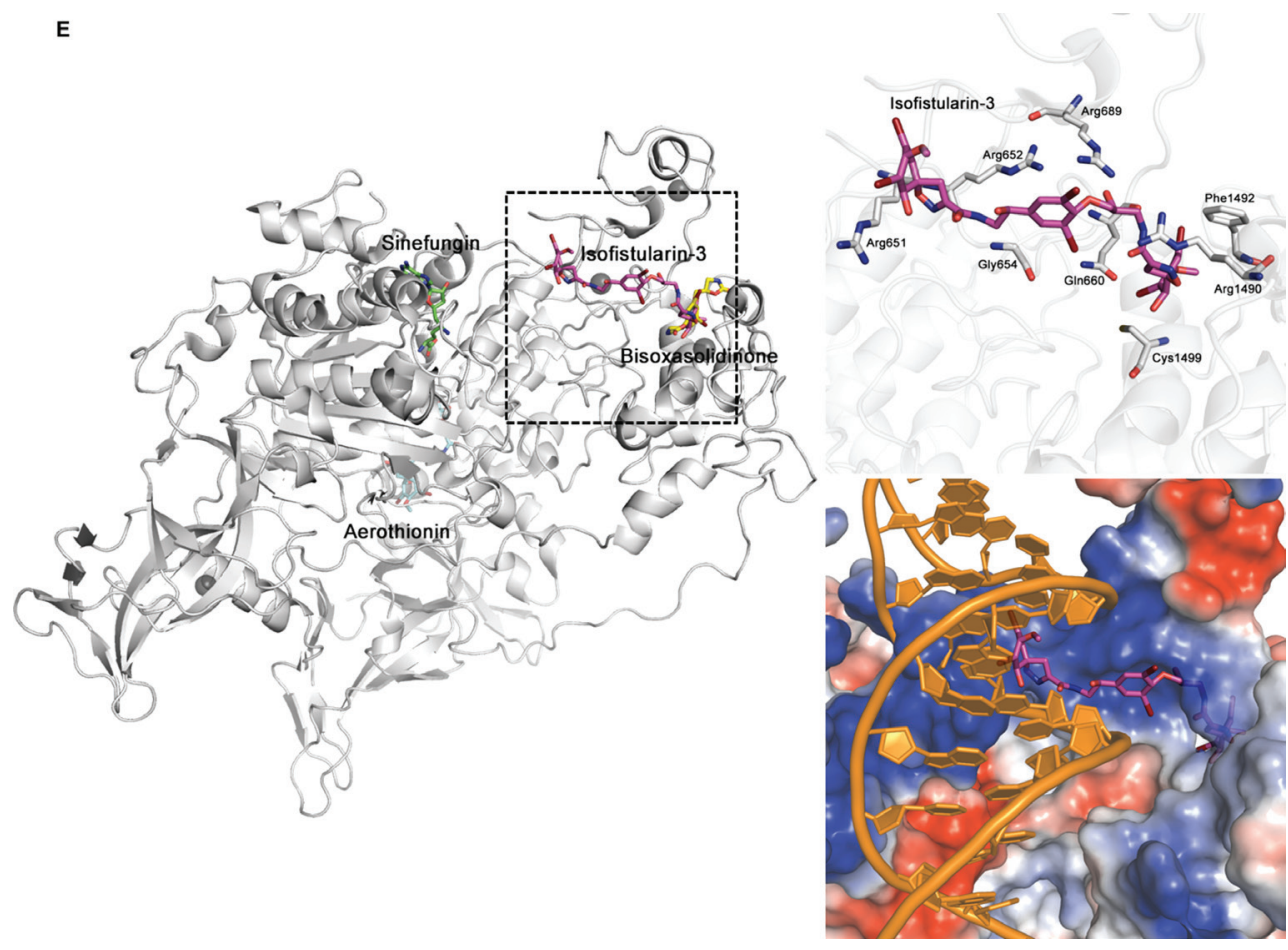

Figure 1: Iso-3 is a new DNMT1 inhibitor interacting with the DNA binding site of DNMT1. (A) Chemical structures of Iso-3, Psammaplin A and bisoxasolidinone. (B) In vitro activity of purified DNMT1 was tested in the presence of increasing concentrations of Iso-3. Data are reported as percentage of DNMT1 activity respect to the control. (C) Iso-3 inhibitory activity against DNMT1 was measured in the presence of increasing concentrations of SAM. (D) In vitro activity of purified DNMT1 in the presence of increasing concentrations of bisoxasolidinone. Histograms represent the mean $\pm \mathrm{SD}$ of three independent experiments. (E) Docking poses of Iso-3, aerothionin, and bisoxasolidinone on the crystal structure of DNMT1 (PDB-Code: 3SWR). DNMT1 protein is represented as cartoon and stick models with carbon, nitrogen, oxygen, and sulphur in white, blue, red, and yellow, respectively. Sinefungin, Iso-3, aerothionin, and bisoxasolidinone are shown as stick models with carbon colored in green, magenta, cyan, and yellow; nitrogen, oxygen, and bromide atoms colored in blue, red, and brown, respectively. Double-stranded DNA model was adopted from the crystal structure of DNMT1-DNA complex (PDB-Code: 3PTA) and colored in orange. Electrostatic potential surface of DNMT1 was calculated and represented as negatively and positively charged surfaces in red and blue shade, respectively. 
receptor (AHR) gene in Burkitt's lymphoma RAJI cells. Several reports established a tumor suppressive activity of this gene [25-27]. Furthermore, hypermethylation and repression of AHR gene were previously reported in various leukemia cell models [28]. Preliminary work conducted by our group suggested that AHR promoter is methylated in RAJI cells; consistently, a strong increase in AHR mRNA expression was obtained by DAC treatment (Figure 2A).

We found that AHR mRNA expression level was 5.1 times higher after $72 \mathrm{~h}$ exposure to $25 \mu \mathrm{M}$ Iso-3 (Figure 2A), a concentration causing a low viability decrease. Next, we performed methylation analysis of AHR promoter $\mathrm{CpG}$ island in RAJI cells. DNA was bisulfite-converted and the fragment of interest was cloned and sequenced. We focused on a 130-nt fragment above the transcription start site, containing $12 \mathrm{CG}$ sites, which belong to the $\mathrm{Sp} 1$ regulatory region of AHR promoter (Figure 2B). Iso-3 treatment resulted in a CG-specific decrease in methylation levels (Figure 2C). The first CG site analyzed (-108) appeared to be the most affected, with $50 \%$ of demethylation with respect to the control sample (Figure 2C). A comparable result at this CG site was obtained with DAC, used as a positive control. In addition, the CGs in positions $-88,-73$ and -60 show a decrease of around $10 \%$ in their methylation levels after Iso-3 treatment. Intriguingly, the most affected CG site $(-108)$ does not belong to a GC-box (Sp1 recognition element) but is located in a flanking position. This result confirms the importance of the methylation status of $\mathrm{CG}$ sites flanking the Sp1 consensus elements, in agreement with several previous reports [29-31].

To attempt to generalize our results, we analyzed AHR mRNA levels in neuroblastoma SH-SY5Y cells, another model lacking AHR expression [32]. DAC treatment increased substantially AHR mRNA level, suggesting for the first time that AHR silencing relies on DNA methylation in this neuroblastoma model. Moreover, treatment with Iso-3 resulted also in a significant AHR mRNA increase in this cell line, to an even stronger degree compared to RAJI cells (increase of 4.25 and 21.5 fold at 5 and $25 \mu \mathrm{M}$, respectively) (Figure 2D). However, we did not observe any increase in Iso-3-treated JURKAT T cells, another AHR-negative DAC-responsive cell line (data not shown).

We next analyzed protein levels of AHR in DACand Iso-3-treated RAJI cells. Despite the mRNA increase obtained with both drugs, we failed to detect AHR protein in any of the treated samples (Supplementary Figure S1B). These data suggest translational inhibition as a secondary mechanism of AHR repression in this cell line, independent of its epigenetic regulation.

Compounds showing DNMT inhibitory activity are often reported to affect DNMT protein levels [33-38]. By analyzing the expression levels of DNMT isoforms in RAJI cells treated with Iso- 3 for 72 hours, we could observe a decrease of DNMT1, whereas other DNMT isoforms were not affected by such treatments (Figure 2E). By analyzing mRNA levels, we found no change in gene transcription that could justify a decrease of DNMT1 protein levels (Supplementary Figure S3A). This decrease appeared nevertheless to be specific for RAJI cells, as we did not detect it in other cell lines, whereas DAC treatment led to DNMT1 degradation in all cell models tested (Figure 2E and Supplementary Figure S3B). In the same context, we observed a decrease of DNMT3A in Iso3-treated JURKAT and HL-60 cells, with appearance of a lower band in HL-60 cells, probably due to high cell death induction and proteolytic cleavage of the protein in this cell line. In the same cell line, DNMT1 protein levels appeared increased (Supplementary Figure S3B).

We further assessed the epigenetic potential of Iso-3 by analyzing its HDAC inhibitory activity. Our data show that Iso-3 has no effect on in vitro total HDAC activity (Figure 2F). Moreover, no increase but rather a decrease of the acetylated form of histone 4 (H4) was recorded in Iso-3-treated RAJI cells, in comparison with the reference pan-HDAC inhibitor suberoylanilide hydroxamic acid (SAHA).

\section{Isofistularin-3 arrests cancer cells in G0/G1 cell cycle phase}

To ascertain the anticancer potential of Iso-3, we treated RAJI and U-937 lymphoma cells with increasing doses of compound. We found a marked reduction of cell proliferation upon Iso-3 treatment in both cell lines (Figure 3A). Proliferation was similarly affected in a broader panel of cancer cell lines (Table 1). By performing cell cycle analysis in RAJI and U-937 cells, we could detect an arrest in the G0/G1 phase of the cell cycle for both cell lines after $24 \mathrm{~h}$ of Iso-3 treatment (Figure 3B and Supplementary Figure S4) with an increase of 55 and $32.8 \%$ cells in $\mathrm{G} 1$ phase at $25 \mu \mathrm{M}$, for RAJI and U-937, respectively. Analysis of genes responsible for cell cycle regulation revealed an increase of p21 and p27 mRNA levels in RAJI cells (3.3- and 3.8-fold increase, respectively); concomitantly, Iso-3 produced a decrease of proliferating cell nuclear antigen (PCNA, 3.6 fold), cyclin E1 (1.6 fold) and c-myc (5.1 fold) mRNA expression levels after $24 \mathrm{~h}$ of treatment (Figure 3C). Analysis of protein expression levels confirmed these results (Figure 3D). These data are in line with the G0/G1 arrest observed.

\section{Isofistularin-3 induces morphological changes and autophagy in RAJI cells}

Furthermore, we performed cellular morphology analysis by microscopic observation in RAJI and U-937 cells. After $24 \mathrm{~h}$ of treatment RAJI cells show negligible viability decrease ( $<10 \%$ trypan blue-positive cells) but 
A

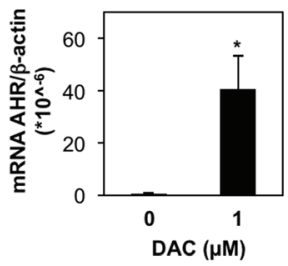

c

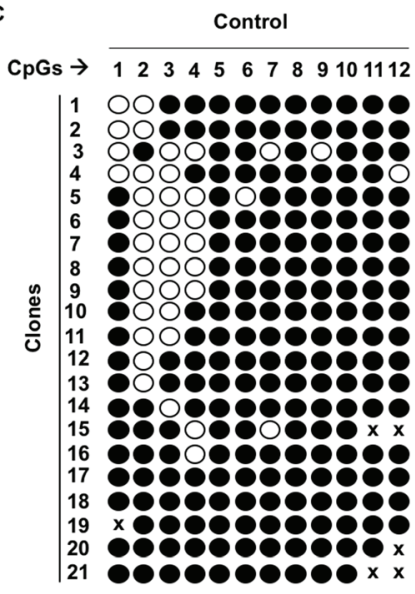

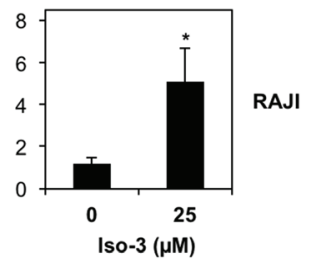

Iso-3 ( $\mu \mathrm{M})$

130 GGGTGGGGCCCTCAAGGAAGACGGAATGGAAT CCÄGATGGGCGGGGGCAAGCAGGACGGGGCGGGG CTACGCGGGATCTGGGCGGGGCGGGGCGGGGCGG GGCCGGTGAGGGGTCGGGGGTGCTCCTGCT_+1
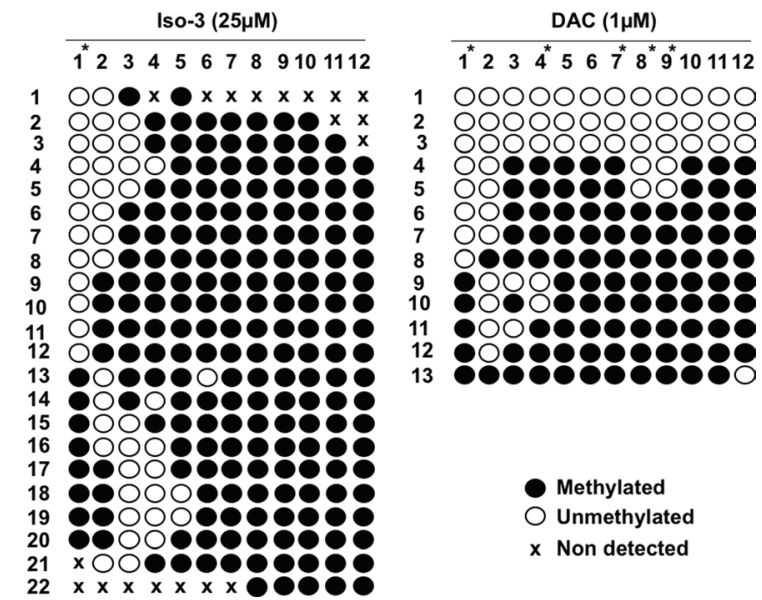

D
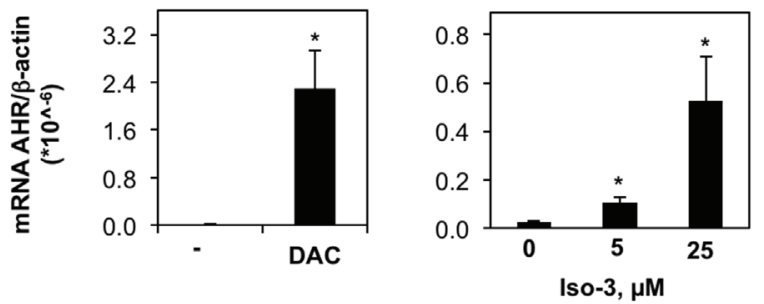

SH-SY5Y

E

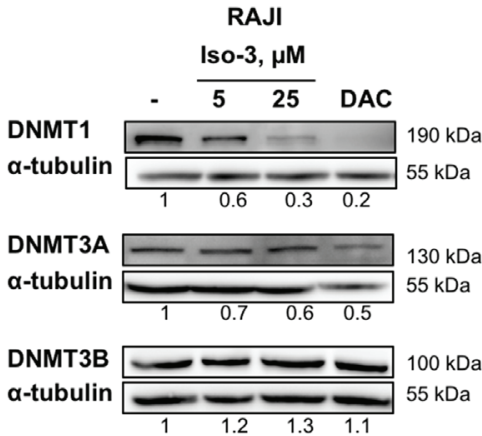

F
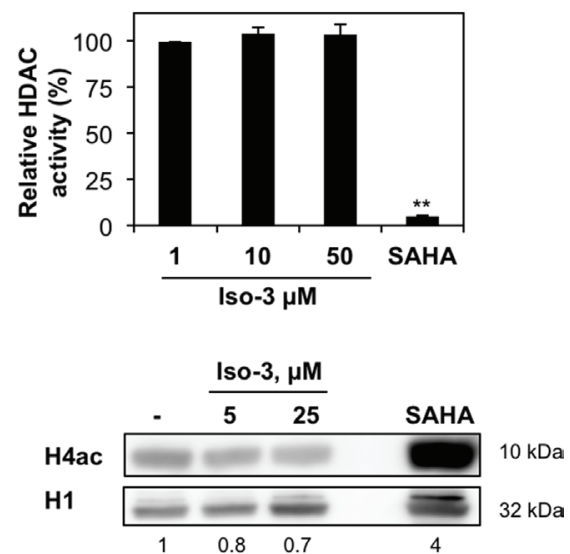

Figure 2: Iso-3 increases AHR expression and induces AHR promoter demethylation. (A) mRNA levels of AHR in RAJI cells measured after $72 \mathrm{~h}$ of treatment with $1 \mu \mathrm{M}$ DAC or $25 \mu \mathrm{M}$ Iso-3. (B) DNA sequence of the AHR promoter region selected for methylation analysis. The underlined sequence corresponds to SNP rs71010234. (C) The methylation pattern of AHR promoter in RAJI cells was revealed upon $72 \mathrm{~h}$ of treatment with Iso-3 or DAC. Results show the methylation status for each of the 12 CpGs upstream of the transcription start site (horizontal numbering), in the different clones sequenced (vertical numbering). Open and closed circles indicate unmethylated and methylated CGs, respectively. (D) mRNA levels of AHR in SH-SY5Y cells measured after $72 \mathrm{~h}$ of treatment with $1 \mu \mathrm{M}$ DAC or indicated Iso-3 concentrations. (E) Protein expression levels of DNMT isoforms in RAJI cells treated $72 \mathrm{~h}$ with Iso-3 at indicated doses or $1 \mu \mathrm{M}$ DAC. (F) Top panel: in vitro total HDAC activity in presence of indicated Iso-3 doses or $2 \mu \mathrm{M}$ SAHA. Data are reported as percentage of HDAC activity respect to the control. Bottom panel: acetylated histone 4 (H4ac) levels in Iso-3- or $2 \mu \mathrm{M}$ SAHA-treated RAJI cells (24 h). Histone H1 (H1) was used as a loading control. All histograms represent the mean \pm SD of three independent experiments. All blots are representative of three independent experiments. 
Table 1: Effect of Iso-3 on the proliferation of various cancer cell lines

\begin{tabular}{|l|l|}
\hline Cell line & GI $_{\mathbf{5 0}}(\boldsymbol{\mu} \mathbf{M}, \mathbf{7 2} \mathbf{~ h})$ \\
\hline RAJI & $9.9 \pm 8.6$ \\
\hline U-937 & $8.1 \pm 5.6$ \\
\hline JURKAT & $10.2 \pm 5.8$ \\
\hline K-562 & $8.3 \pm 3.6$ \\
\hline MEG-01 & $14.8 \pm 5.3$ \\
\hline HL-60 & $8.1 \pm 4.7$ \\
\hline SH-SY5Y & $>50^{s}$ \\
\hline PC-3 & $8.1 \pm 4.4$ \\
\hline MDA-MB-231 & $7.3 \pm 7.0$ \\
\hline
\end{tabular}

$(\$ 41.1 \pm 7.7 \%$ growth inhibition at $50 \mu \mathrm{M})$.

Data are the mean $\pm \mathrm{SD}$ of growth inhibitory dose $50 \%\left(\mathrm{GI}_{50}\right)$ values calculated from at least three independent experiments.

overt morphological changes characterized by a strong size increase and the appearance of cytoplasmic vacuoles (Figure 4A). A marked increase in size, and to a lesser extent in granularity, was confirmed by quantification of FSC and SSC parameters by flow cytometry (Figure 4B). Morphological changes were less evident in U-937 cells (Figure 4A). These features prompted us to investigate the appearance of autophagic markers upon Iso-3 treatment. LC3 conversion was assessed by Western blotting and revealed appearance of the converted LC3-II form in RAJI cells exposed to different Iso-3 concentrations for $24 \mathrm{~h}$. Co-treatment of cells with the inhibitor of late steps of autophagy, bafilomycin $A_{1}$, further enhanced the signal (Figure 4C). Moreover, treatment with $15 \mu \mathrm{M}$ Iso-3 for $12 \mathrm{~h}$ revealed accumulation of LC3-II in the presence of bafilomycin $A_{1}$, suggesting an early induction of the autophagic flux (Supplementary Figure S5A). Fluorescence microscopy analysis of RAJI cells stained with Cyto-ID ${ }^{\circledR}$ allowed quantification of vacuoles associated with the autophagic pathway; the percentage of cells presenting autophagic vesicles was 7 times higher in Iso-3-treated cells than in control cells (Figure 4D). To further confirm autophagy induction, we performed transmission electron microscopy analysis of cells after $24 \mathrm{~h}$ of treatment with Iso-3. The analysis of cellular structures [39] revealed the appearance of an extensive autophagocytic vacuolization in RAJI cells (Figure 4E), leading in extreme cases to autophagic cell death, characterized by depletion of organelles and absent or non-pyknotic nuclei (Supplementary Figure S5B). The appearance of autophagic features was less pronounced in U-937 cells (Figure 4E).

\section{Isofistularin-3 induces caspase-dependent and -independent cell death}

It is well known that prolonged proliferation arrest and/or onset of autophagy may trigger cell death. Thus, we tested the effect of Iso-3 on cell viability after extended periods of treatment. Trypan blue analysis of RAJI and U-937 cells revealed a fraction of cells starting to undergo cell death after $72 \mathrm{~h}$ of treatment (Figure 5A). Western blot analysis for caspase and poly-(ADPribose) polymerase-1 (PARP-1) cleavage showed robust cleavage in U-937 cells at the highest Iso-3 concentration, whereas a weaker cleavage was observed in RAJI cells (Figure 5B). Subsequently, we investigated RAJI and U-937 nuclear morphology by Hoechst-propidium iodide (PI) staining after $72 \mathrm{~h}$ of treatment with $50 \mu \mathrm{M}$ Iso-3, in presence of the pan-caspase inhibitor ZVAD-FKM or the necroptosis inhibitor Necrostatin-1, respectively. Results show the appearance of apoptotic nuclei in both cell lines, and of a fraction of non apoptotic-PI positive nuclei in RAJI cells. The pan-caspase inhibitor ZVAD-FKM was able to prevent apoptotic cell death in RAJI but not in U-937 cells, suggesting a switch to a caspase-independent type of apoptosis upon prolonged Iso-3 treatment in this cell line. Necrostatin-1 failed to prevent Iso-3-induced cell death in any of the cell lines tested (Figure 5C).To confirm the potential of Iso-3 to impair the replicative ability of cancer cells, we investigated RAJI, U-937 and prostate cancer PC-3 cells colony formation ability in the presence of increasing concentrations of compound. Colony formation was strongly reduced by Iso-3 at $15 \mu \mathrm{M}$ and almost completely abolished at $25 \mu \mathrm{M}$, in all cell lines (Figure 5D). 
Viability was also decreased to various extents in a panel of other cancer cell lines, but not in peripheral blood mononuclear cells (PBMCs) isolated from healthy donors (Figure 5E). Furthermore, we provide evidence that Iso3 did not trigger acute toxicity in the context of zebrafish development, as shown by the absence of morphological defects and no occurrence of dead embryos, even at the highest concentration used, after $24 \mathrm{~h}$ of treatment (Figure 5F).

To extend our colony formation assays to an in vivo setting, we compared the capacity of Iso-3 to abrogate tumor formation in a zebrafish xenograft model. Our results show a dose-dependent inhibition of tumor formation when we injected Iso-3-pretreated fluorescent PC-3 and SH-SY-5Y cancer cells (Figure 5G and Supplementary Figure S6) thus validating our in vitro results.

\section{Isofistularin-3 sensitizes lymphoma cells to TRAIL-induced apoptosis}

Combination treatments represent a promising and increasingly pursued strategy in anticancer therapy, especially in cancer presenting TRAIL resistance. As G0/ G1 cell cycle arrest was previously reported to sensitize cancer cells against TRAIL [40] and epigenetic modulators were often reported to be TRAIL sensitizers [41, 42], we assessed the effect of Iso-3 on cancer cell viability after combination treatments with TRAIL. We pre-treated RAJI and U-937 cell lines with sub-toxic concentrations of Iso-3 for 24 hours, then we treated cells at indicated doses of TRAIL and measured the effects 24 hours after addition. TRAIL concentrations were chosen according to the differential sensitivity of the two cell lines reported in the literature and verified by own work.

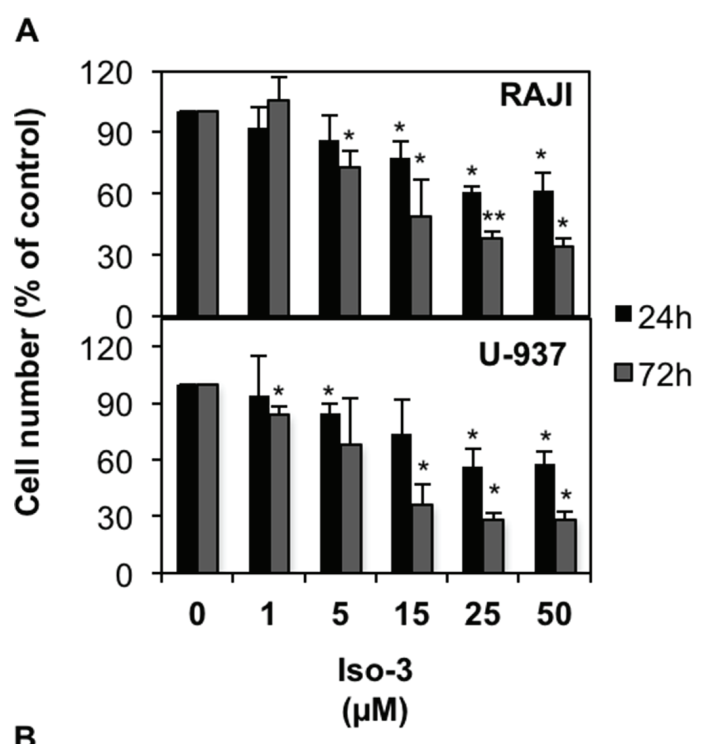

B

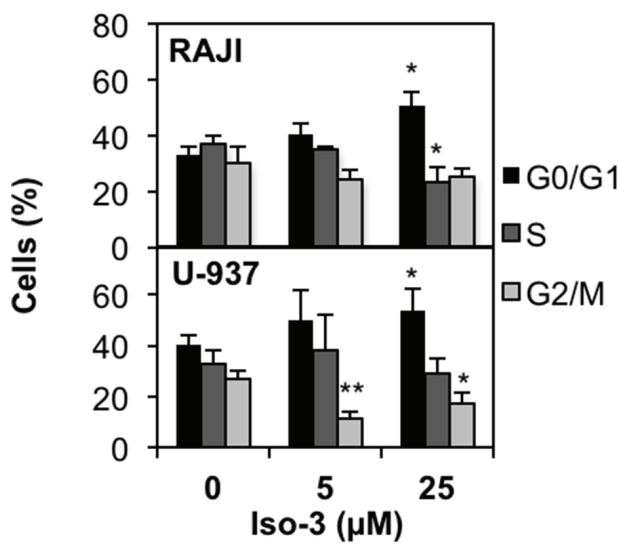

C

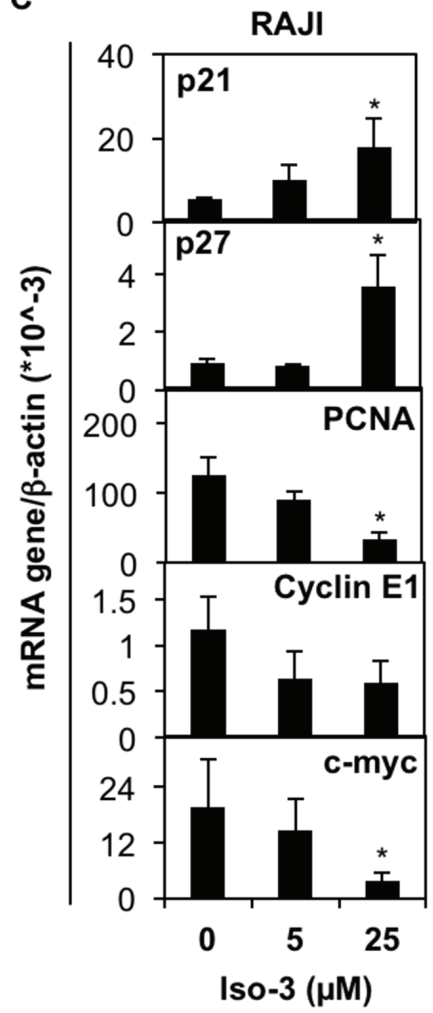

D

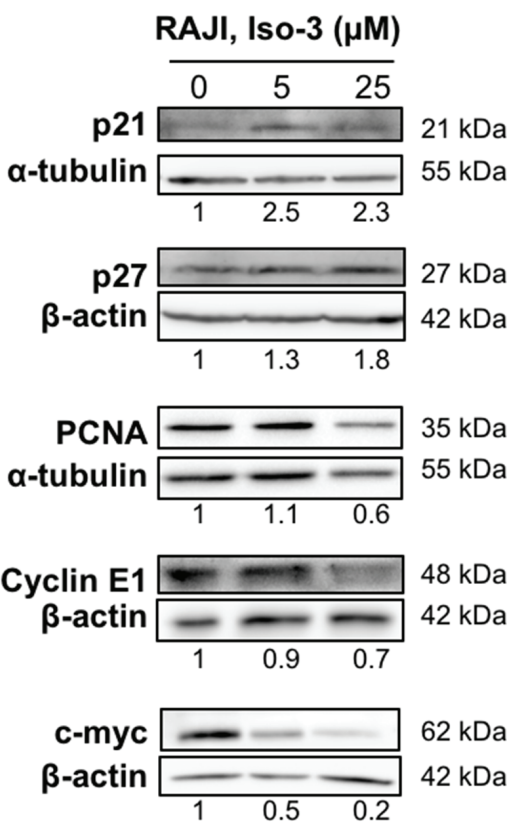

RAJI, Iso-3 ( $\mu \mathrm{M})$

$1 \mathrm{kDa}$ 55 kDa

$\mathrm{kDa}$

(1)

$\mathrm{kDa}$ $2 \mathrm{kDa}$

$\mathrm{kDa}$ $\mathrm{kDa}$

Figure 3: Iso-3 arrests cancer cells in the G0/G1 phase of cell cycle. (A) RAJI and U-937 cells were treated with Iso-3 and cell number was evaluated after 24 and $72 \mathrm{~h}$. (B) RAJI and U-937 cells treated with Iso-3 for $24 \mathrm{~h}$ were analyzed for DNA content by flow cytometry. Bars represent the percentage of cells in each cell cycle phase. (C) mRNA and (D) protein expression levels of cell cyclerelated genes in RAJI cells treated with Iso-3 for $24 \mathrm{~h}$. Histograms represent the mean \pm SD of three independent experiments. Blots are representative of three independent experiments. 
Results revealed that the viability was not significantly affected by TRAIL or Iso-3 treatments alone (Figure 6A). Conversely, pre-treatment with Iso-3 followed by TRAIL exposure produced a marked decrease of cell viability for both models (Figure 6A). Combination index (CI) [43] shows synergism for these two agents at several dose combinations (Table 2). The Iso-3 dose of $15 \mu \mathrm{M}$ resulted in the strongest synergism $(\mathrm{CI}=0.22$ with $50 \mathrm{ng} / \mathrm{ml}$ TRAIL in RAJI; CI $=0.21$ with $5 \mathrm{ng} / \mathrm{ml}$ TRAIL in U-937). In contrast, simultaneous treatment of RAJI cells with both drugs failed to affect cell viability, suggesting that early effects produced by Iso-3 are necessary for TRAIL sensitization (Figure 6B). Importantly, we showed that Iso-3 pre-treatment did not sensitize PBMCs from healthy donors to TRAIL (Figure 6C). Subsequently, we analyzed the typology of cell death produced by the combination treatment, focusing on the most interesting combination doses (Figure 6D). The results of nuclear morphology analysis revealed the induction of apoptosis in both cell lines. Activation of effector caspases (3/7) was confirmed by caspase activity assay (Figure 6E, right panel) and western blot analysis revealed that caspase 8 , caspase 3 and PARP-1 were efficiently cleaved after Iso-3 plus TRAIL treatment in RAJI cells, as shown by a strong decrease of pro-caspase bands and appearance of active caspase 3 fragments. Conversely, no decrease of the procaspase 9 was recorded, suggesting that the extrinsic apoptotic pathway alone was implicated in the induced cell death (Figure 6E, left panel). Apoptosis induction was further confirmed by the concomitant use of the pan- caspase inhibitor ZVAD-FKM, which greatly reduced the amount of cell death and prevented caspase activation, as well as PARP cleavage (Figure 6D, 6E, 6F).

To investigate the mechanism of TRAIL sensitization by Iso-3, we first analyzed expression levels of several proteins known to play important roles in TRAIL resistance [44]. First, we did not detect any changes in the expression levels of antiapoptotic Bcl-2 family proteins, nor of the inhibitor of apoptosis (IAP) X-linked-IAP (XIAP) (Figure 6F). In contrast, we detected a decrease in the expression levels of the IAP survivin as well as of cellular FLICE-like inhibitory protein (FLIP) (Figure 6G). FLIP down-regulation was previously reported under endoplasmic reticulum (ER) stress conditions $[45,46]$ and many ER stress-inducing drugs were shown to sensitize cancer cells to TRAIL [47]. Thus, we verified levels of the ER chaperone GRP78 upon Iso-3 treatment, as a marker of ER-stress induction. We found a strong dose-dependent increase in GRP78 expression levels (Figure 6G) supporting the idea that Iso-3-treated RAJI cells undergo ER stress. In accordance, treatment of cells with $15 \mu \mathrm{M}$ Iso-3 for $48 \mathrm{~h}$ resulted in increased CCAAT-enhancer-binding protein homologous protein (CHOP) and death receptor (DR)5 mRNA expression (Figure 6H). Finally, we verified surface expression levels of both functional TRAIL receptors, DR4 and 5. Our results show that treatment with $15 \mu \mathrm{M}$ Iso-3 increased DR5 surface expression levels by around 30\%, whereas DR4 surface levels were unchanged (Figure 6I).

A
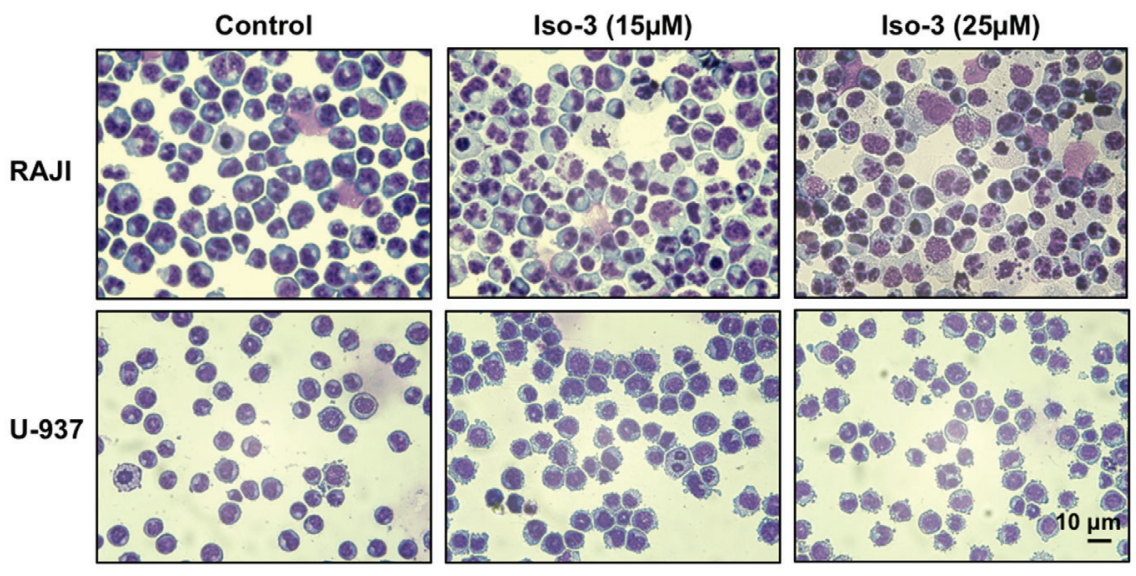

B
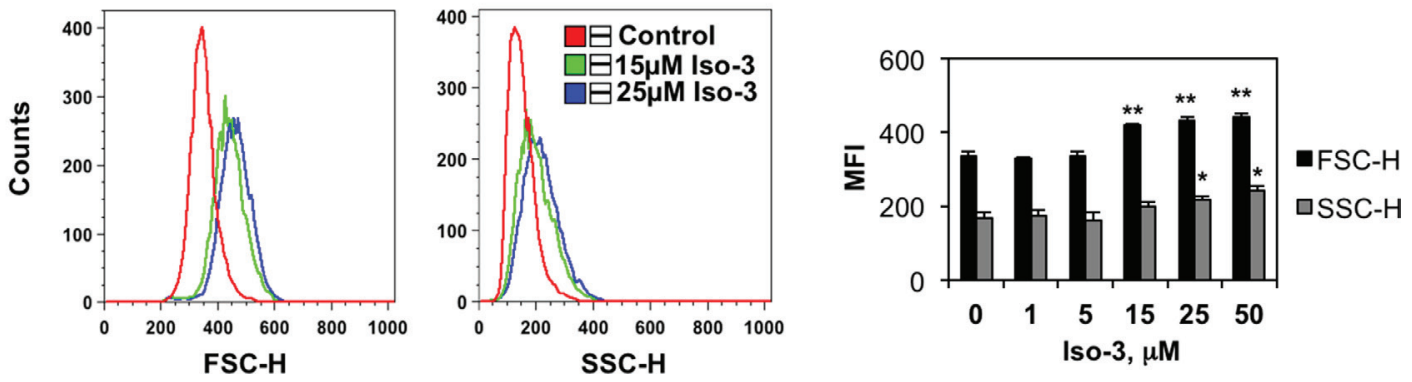

www.impactjournals.com/oncotarget 
C

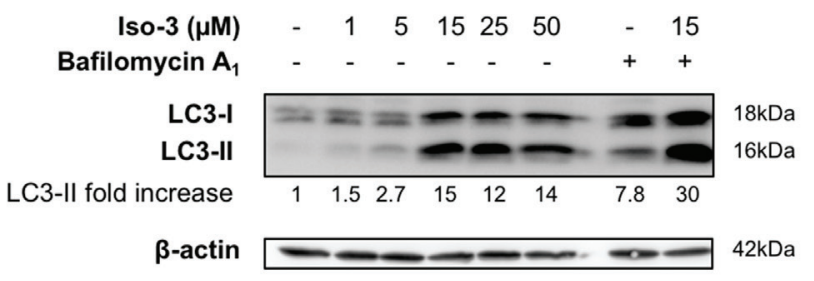

D
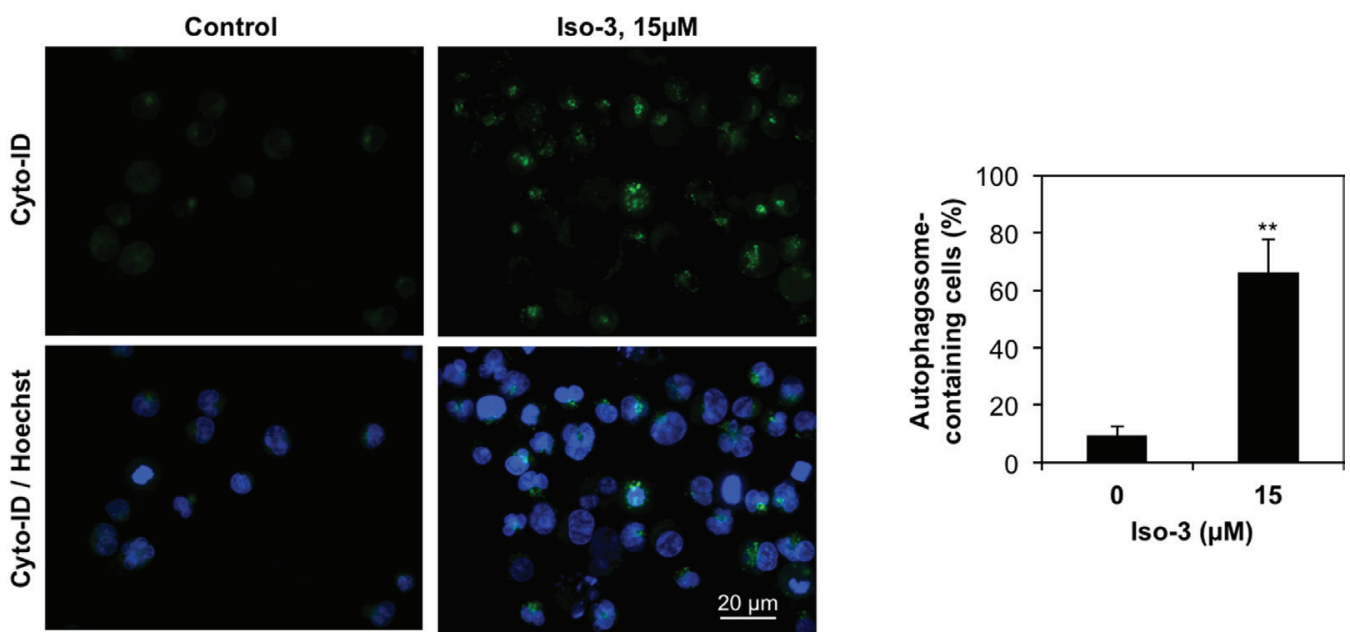

E
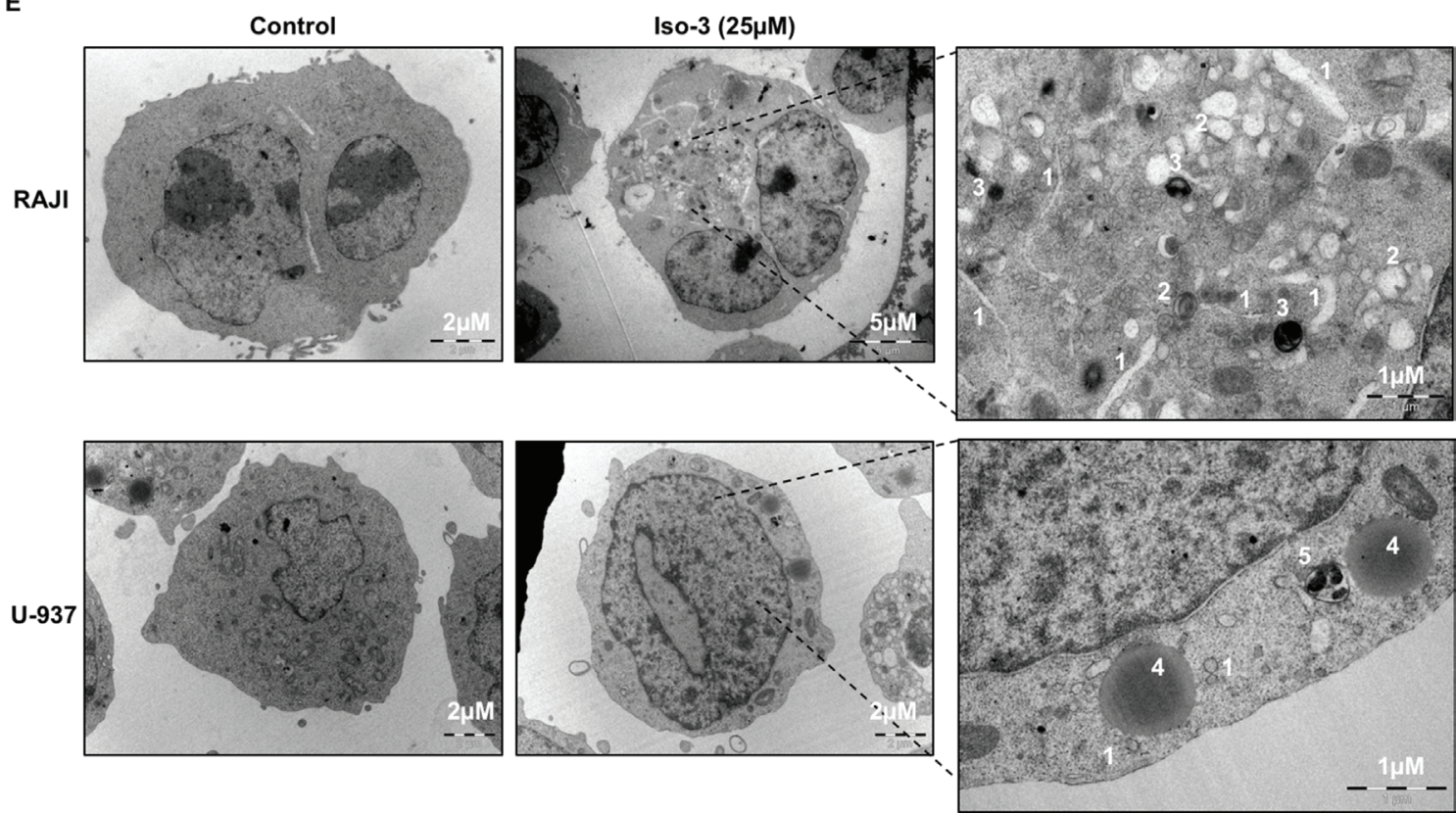

Figure 4: Iso-3 induces autophagy in lymphoma cells. (A) Morphological analysis was performed by Diff-Quik staining and microscopic observation of RAJI and U-937 cells after $24 \mathrm{~h}$ of treatment with Iso-3. (B) Cellular size (forward scatter, FSC) and granularity (side scatter, SSC) were measured by flow cytometry in RAJI cells treated for $24 \mathrm{~h}$ with Iso-3. (C) Western blot analysis of LC3 conversion in RAJI cells treated with different concentrations of Iso-3 for $24 \mathrm{~h}$. Where indicated, bafilomycin $\mathrm{A}_{1}$ ( $40 \mathrm{nM}$ ) was added $2 \mathrm{~h} \mathrm{before}$ harvesting. Blots are representative of three independent experiments. (D) RAJI cells where treated or not with Iso-3 for $24 \mathrm{~h}$, then stained with Cyto-ID ${ }^{\circledR}$ Green dye as described in the materials and methods section, and appearance of autophagosome-related vesicles was observed by fluorescence microscopy. Representative images and quantification of autophagosome-positive cells are provided. (E) Representative images of electron microscopy analysis of RAJI and U-937 cells treated or not for $24 \mathrm{~h}$ with Iso-3. (1) Phagophores, (2) autolysosomes of different maturity, (3) residual bodies, (4) lysosomes, (5) multivesicular body. All histograms represent the mean \pm SD of three independent experiments. All blots are representative of three independent experiments. 

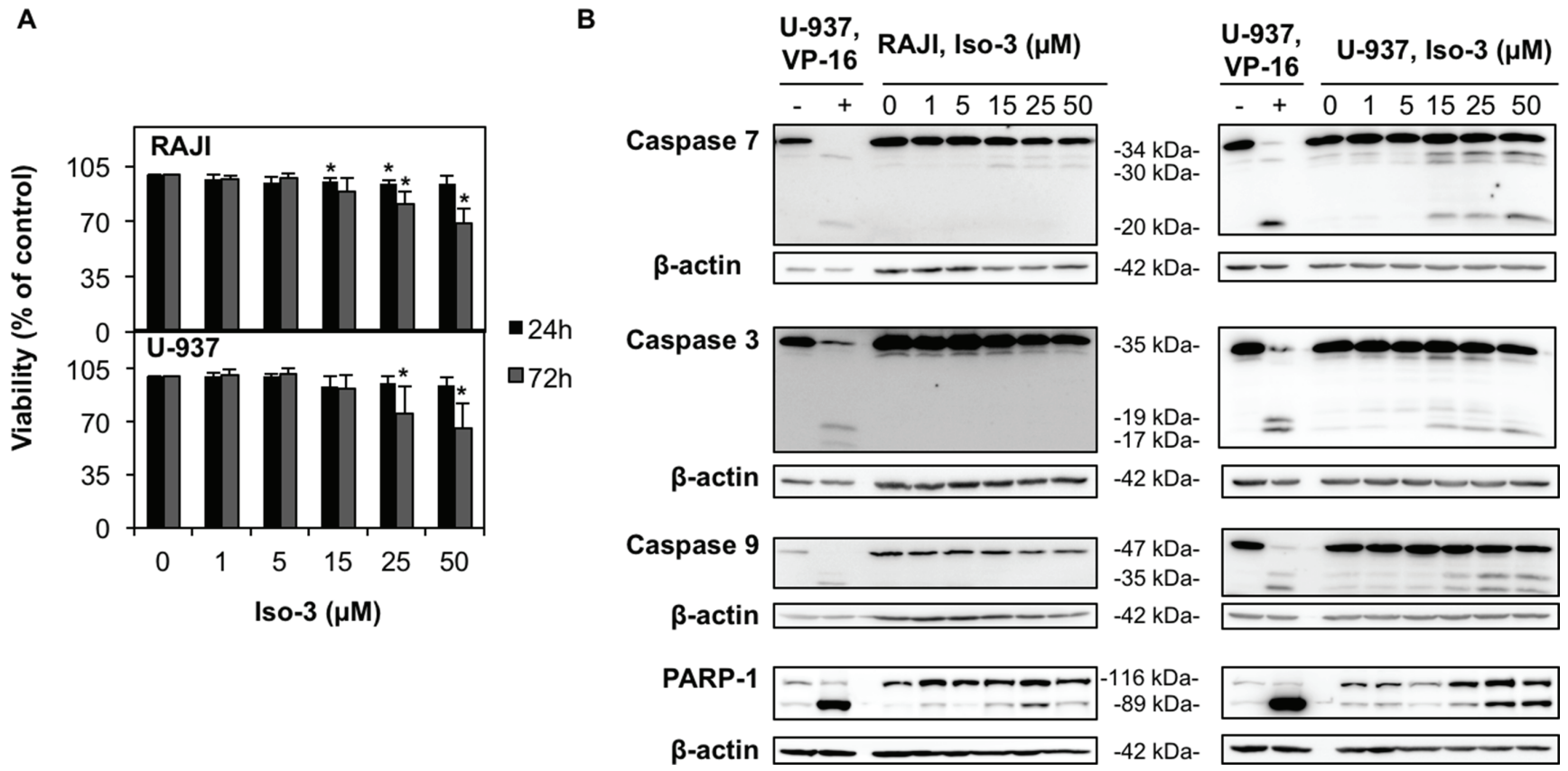

C

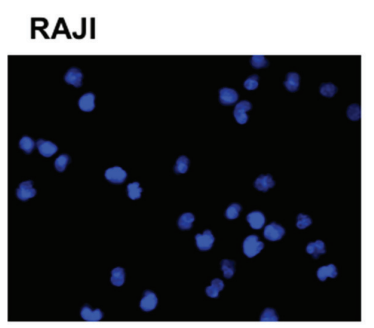

\section{U-937}
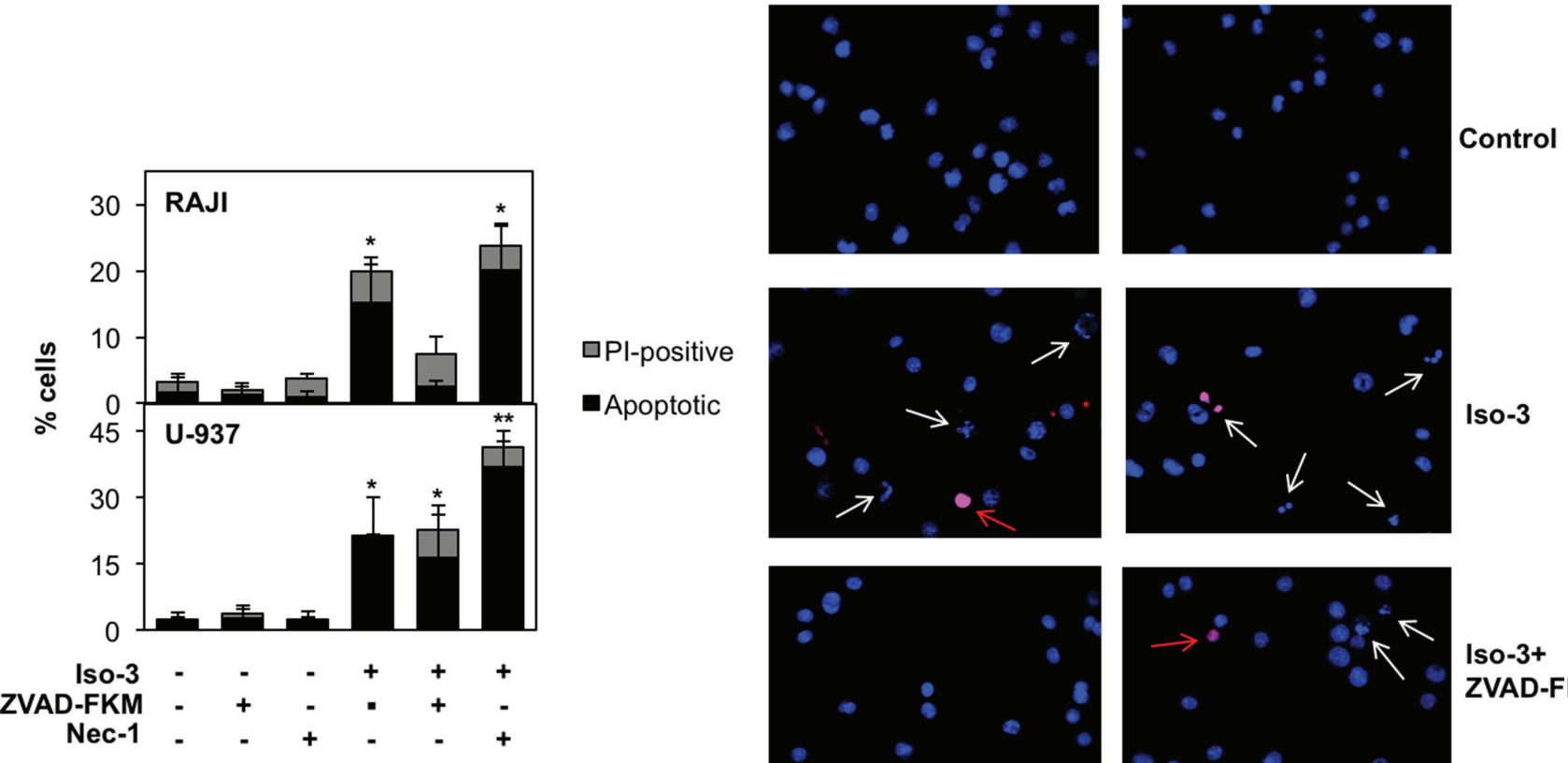

Iso-3

-Apoptotic
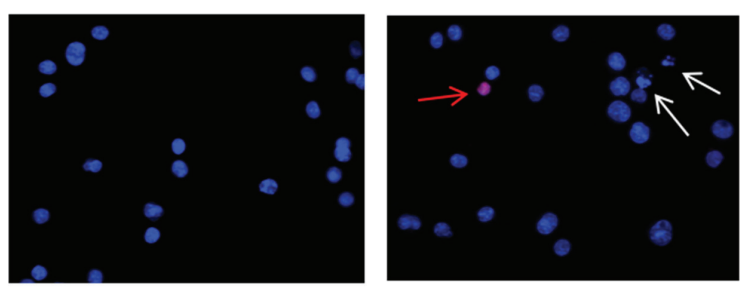

Iso-3+

ZVAD-FKM
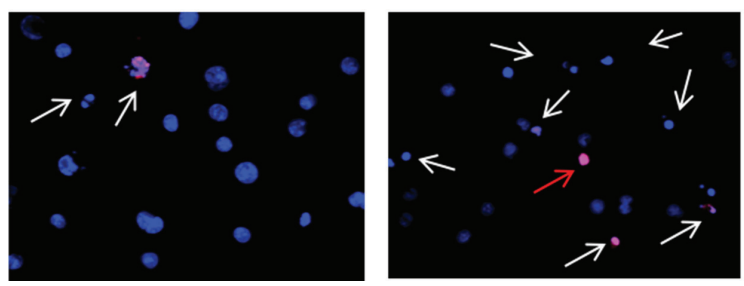

Iso-3+

Nec-1 

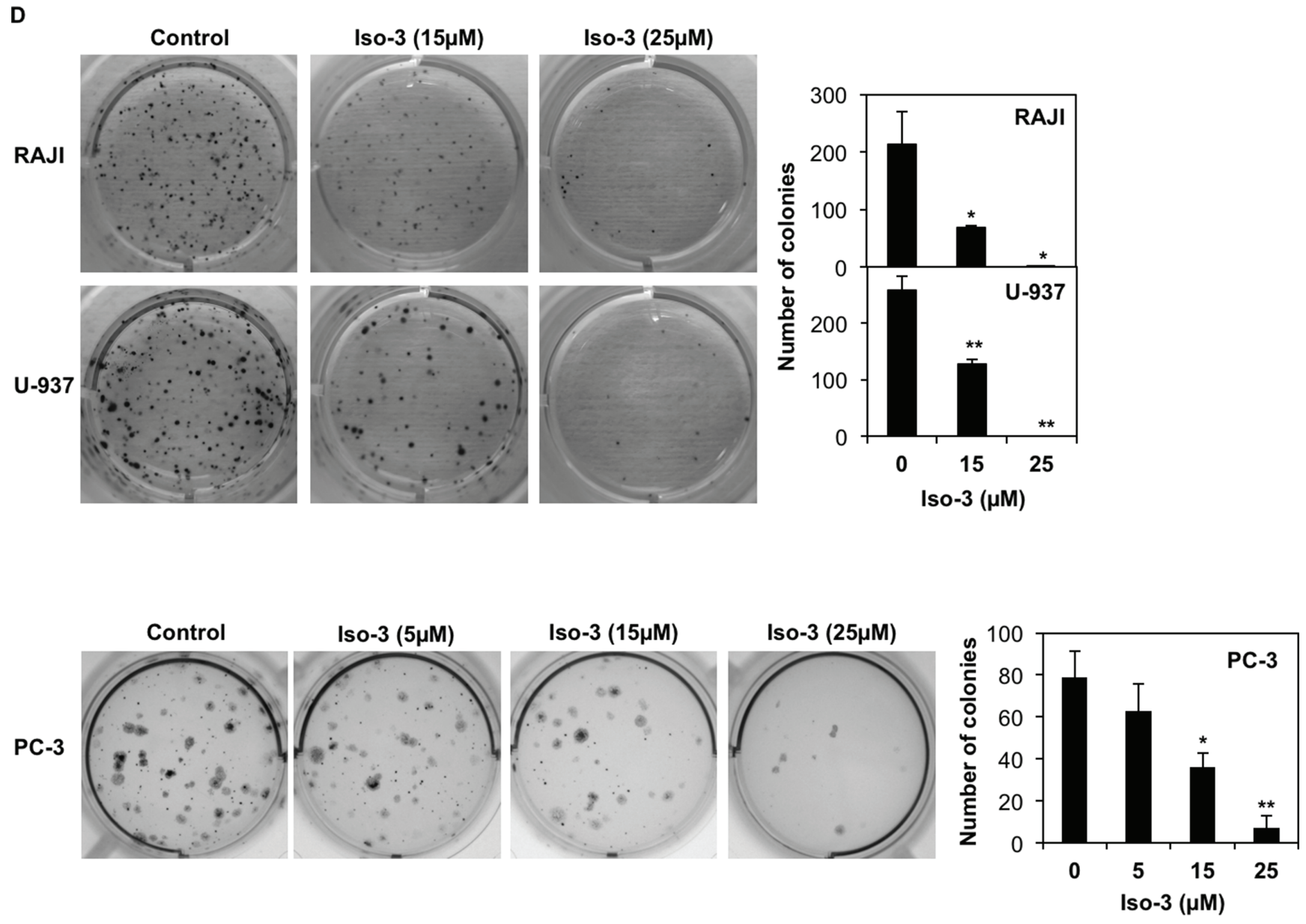

E
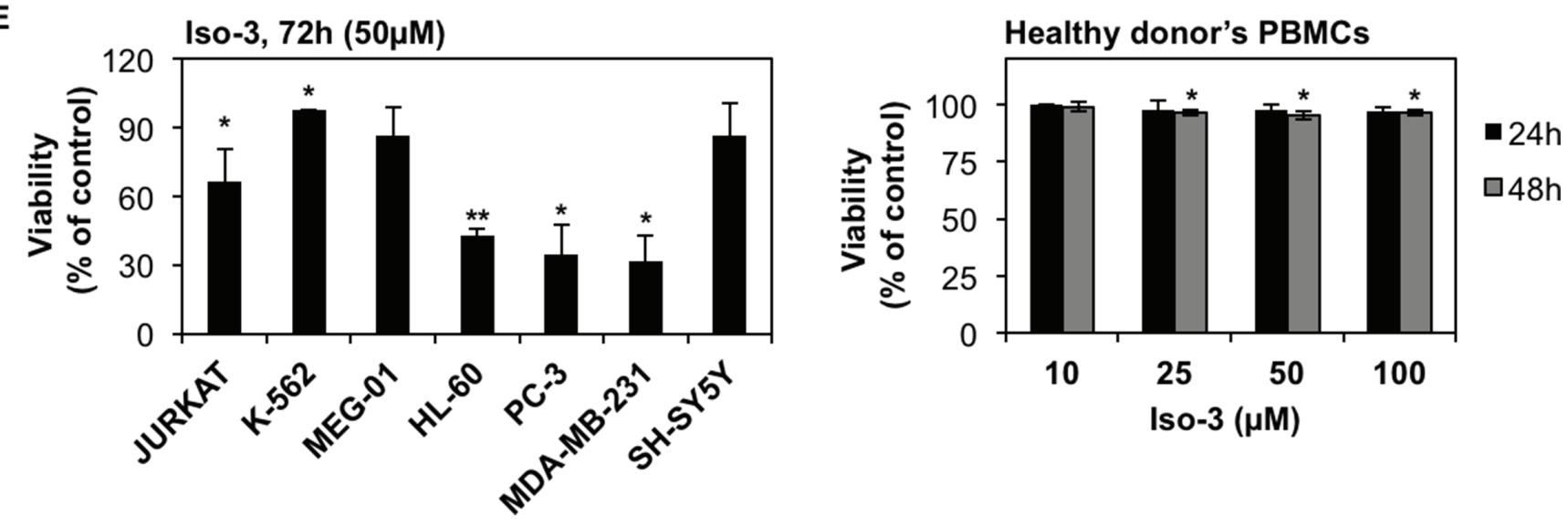
$\mathbf{F}$

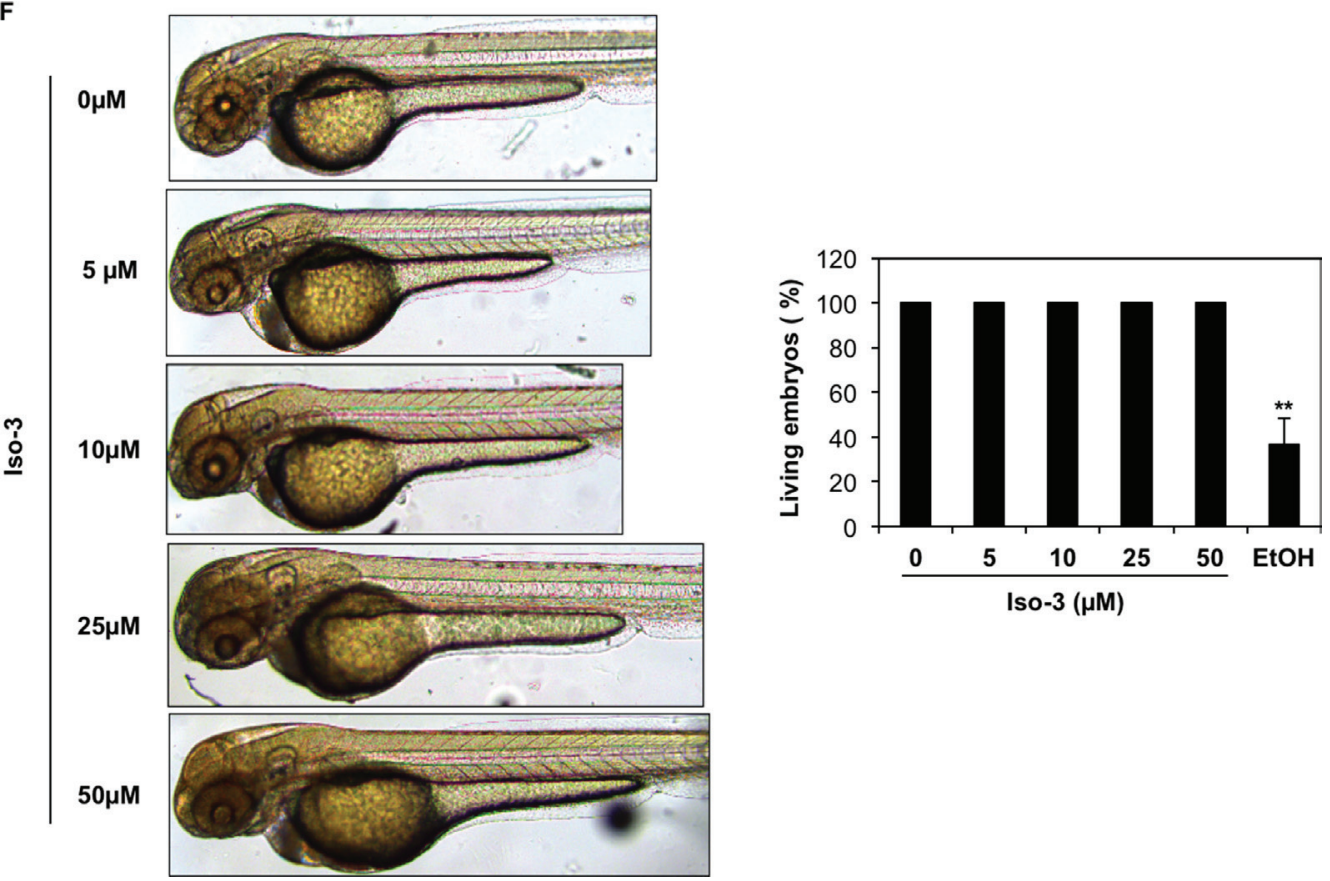

G
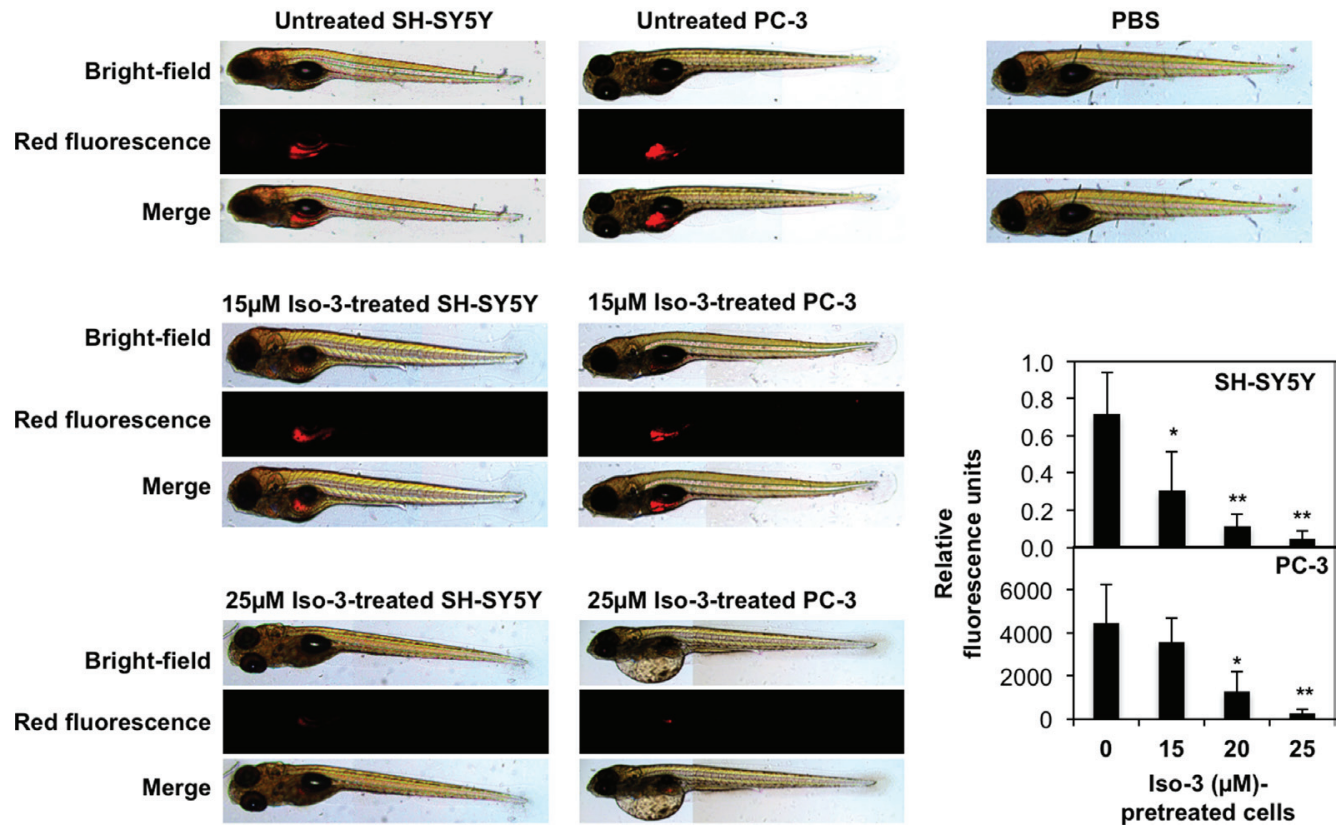

Figure 5: Effect of Iso-3 on cell viability. (A) The viability of RAJI and U-937 cells was measured by trypan blue exclusion assay after 24 and $72 \mathrm{~h}$ of exposure to Iso-3. (B) Western blot analyses of caspase activation and PARP-1 cleavage in RAJI and U-937 cells treated for $72 \mathrm{~h}$ with Iso-3. U-937 cells, untreated or treated with $100 \mu \mathrm{M} \mathrm{VP}-16$ for $3 \mathrm{~h}$, were used as negative and positive controls for caspase cleavage, respectively. (C) Hoechst-PI staining of RAJI and U-937 cells treated with $50 \mu \mathrm{M}$ Iso-3 for 72 hours. Apoptotic and non-apoptotic PI-positive nuclei are reported as a percentage of the total number of cells. ZVAD-FKM $(50 \mu \mathrm{M})$ and Necrostatin-1 (Nec-1; $30 \mu \mathrm{M})$ were added $1 \mathrm{~h}$ before Iso-3 treatment, where indicated. White arrows: apoptotic cells. Red arrow: PI-positive cells. Pictures are representative of three independent experiments (D) RAJI, U-937 and PC-3 cells were grown in the presence of Iso-3 for 10 days and colony formation was then scored. (E) Trypan blue scored viability of a panel of cancer cell lines (left) and of PBMCs from healthy donors after Iso-3 treatment at the indicated time points and doses. (F) Representative images of Zebrafish embryos after $24 \mathrm{~h}$ treatment with the indicated Iso-3 doses (right panel) and corresponding quantification of viable embryos percentage (left panel). Ethanol 3\% (EtOH) was used as a positive control for toxicity. (G) Fluorescent SH-SY5Y or PC-3 cells were treated or not in vitro at different concentrations of Iso-3 for $24 \mathrm{~h}$ and then injected in the zebrafish yolk sac. Fluorescence was quantified. Representative images from a total of six to nine fish per condition. Fluorescence intensity quantification graphs are shown. PBS injection was used as a control for injection toxicity. All histograms represent the mean $\pm \mathrm{SD}$ of three independent experiments. All blots are representative of three independent experiments. 


\section{DISCUSSION}

DNMT inhibitors reported in the literature include a variety of molecules with very different chemical structures. Compounds shown to behave as DNMT inhibitors include an increasing number of natural molecules [6-8], all of which raised a huge interest for their ability to demethylate and re-activate specific TSGs in different cell lines. Such effects are believed to participate in the antitumor or tumor-preventive effects of these compounds. We showed here that Iso-3, a brominated alkaloid from the sponge Aplysina aerophoba, is able to inhibit DNMT1 activity in vitro. Docking studies suggest that Iso-3 is a direct, DNAcompetitive, DNMT1 inhibitor. A similar mode of action was recently demonstrated for another natural DNMT inhibitor, laccaic acid A [48]. Despite some structure similarities with the dual HDAC and methyltransferase inhibitor bromotyrosine derivative PsA, we did not find evidence that Iso-3 functions as an HDAC inhibitor. This is most likely due to the absence of the thiol linker moiety present in PsA.

DNMT inhibition should lead to a decrease of DNA methylation at some genetic locus. Here, we show that Iso-3 induces AHR promoter demethylation and restores mRNA re-expression in RAJI cells. AHR is a ligandactivated transcription factor, known for its role in the detoxification from environmental carcinogens. More

A

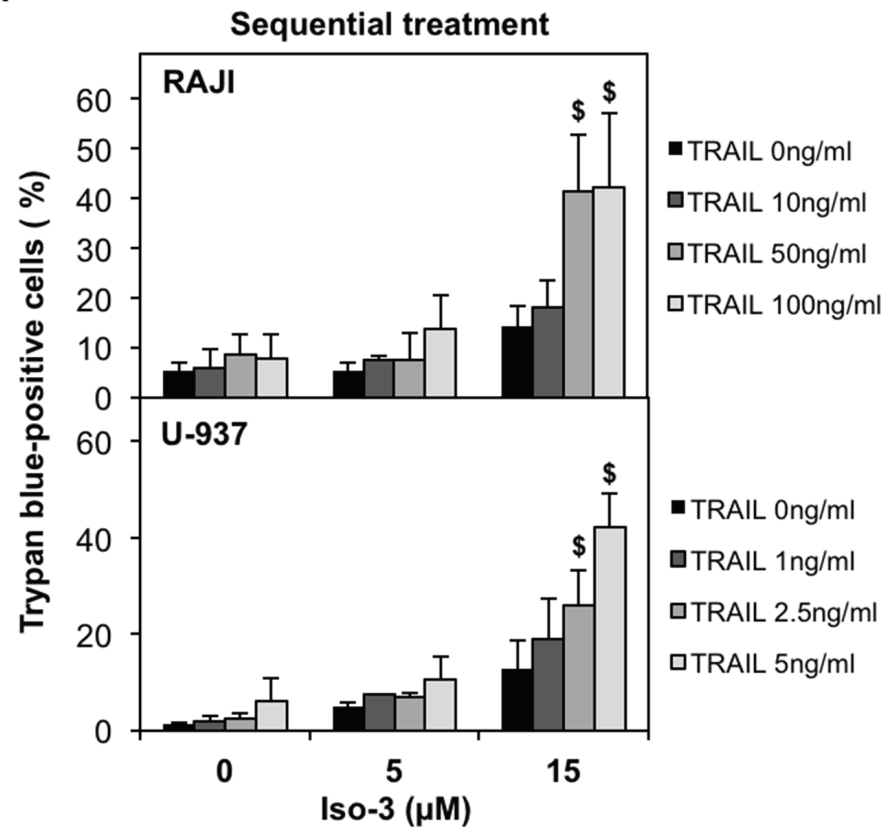

importantly, AHR is implicated in numerous other cellular functions such as cell cycle regulation and immune functions $[27,49,50]$. Several reports established a tumor suppressive activity of this gene [25-27]. The finding that AHR is hypermethylated and repressed in several acute lymphoblastic leukemia (ALL) cell lines and in patients [28] reinforced the idea that AHR repression contributes to malignancy in these models. Previous work showed that RAJI cells do not express AHR [51]. Here, we report for the first time promoter hypermethylation as a mechanism for AHR repression in a Burkitt's lymphoma model. We also detected for the first time in RAJI cells the presence of a GGGGC(2×) repeat insertion in the $\mathrm{Sp} 1$ region of AHR promoter (SNP rs71010234) (Figure 2A), a SNP previously reported for other cancer cell lines and human samples [52-54].

In this study, treatments with Iso-3 led to decrease methylation at specific CG sites in the AHR promoter. Intriguingly, the most affected CG site by Iso-3 is located near $\mathrm{Sp} 1$ consensus elements, confirming that methylation of CG sites flanking the Sp1 consensus seem to be most important in affecting Sp1 binding. Our results suggest that Iso-3-induced demethylation contributes to the increase of AHR expression achieved. AHR protein was undetectable in Iso-3- as well as DAC-treated samples despite increased mRNA levels: we hypothesize that in addition to promoter methylation, a translational inhibitory mechanism regulates AHR expression in these cells.
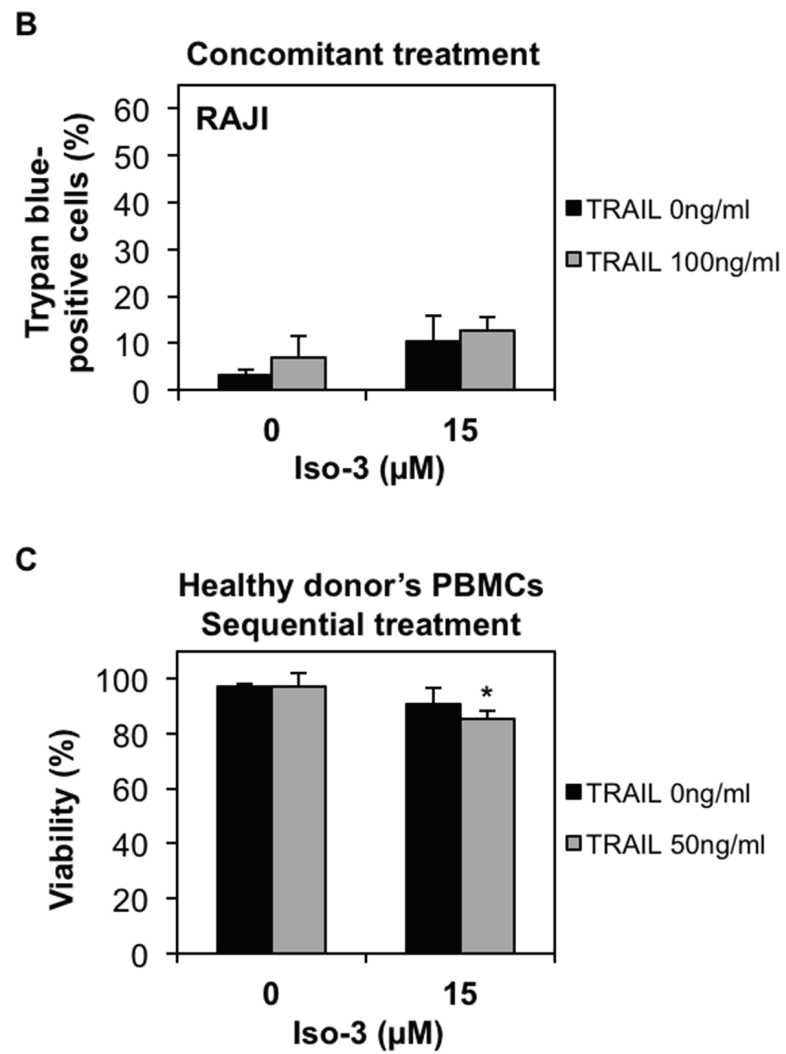
D
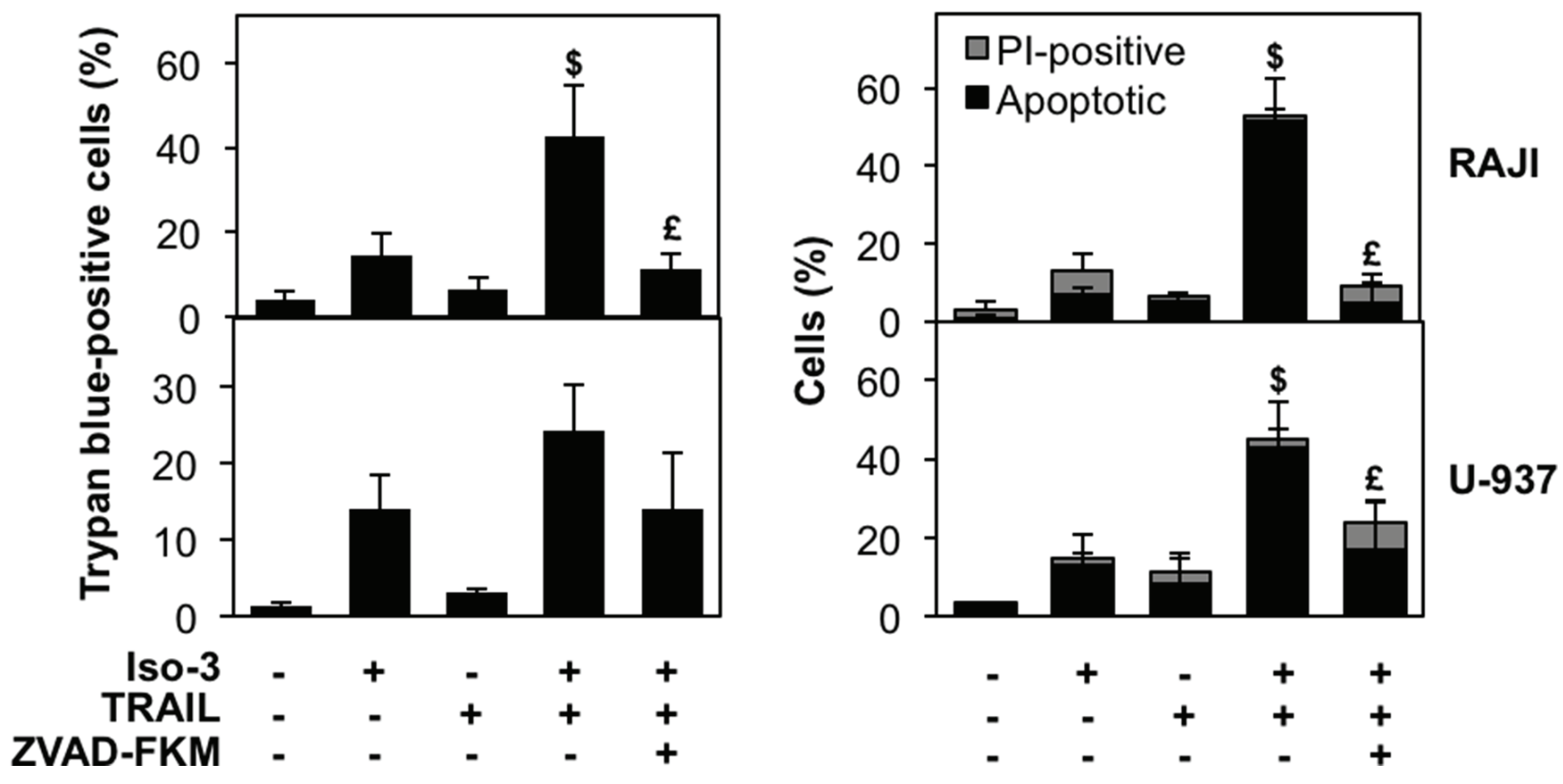

E
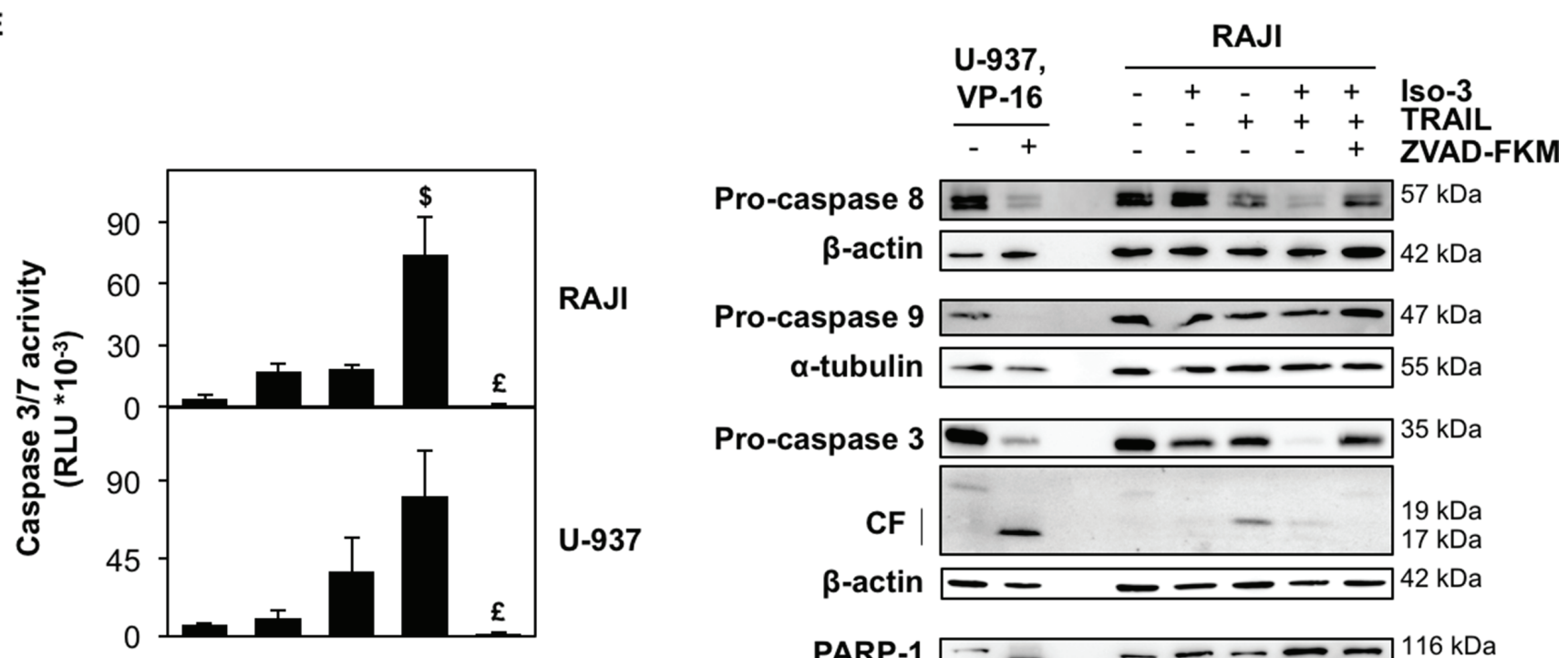

RAJI

$\beta$-actin

$\because-\infty 42 \mathrm{kDa}$

Pro-caspase $9 \longrightarrow-\longrightarrow 47 \mathrm{kDa}$ a-tubulin $\longrightarrow--\infty 55 \mathrm{kDa}$

Pro-caspase $3 \square-\infty-\infty \mathrm{kDa}$

U-937

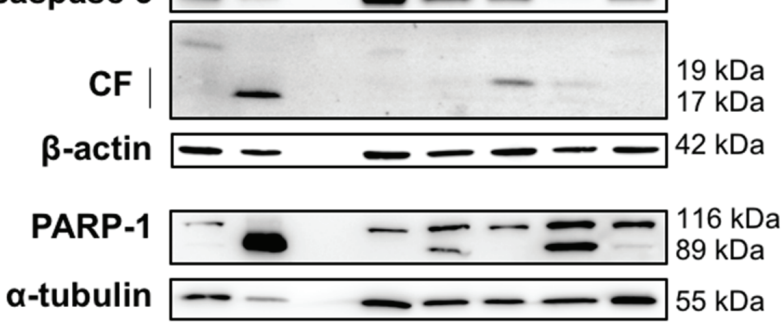


$\mathbf{F}$

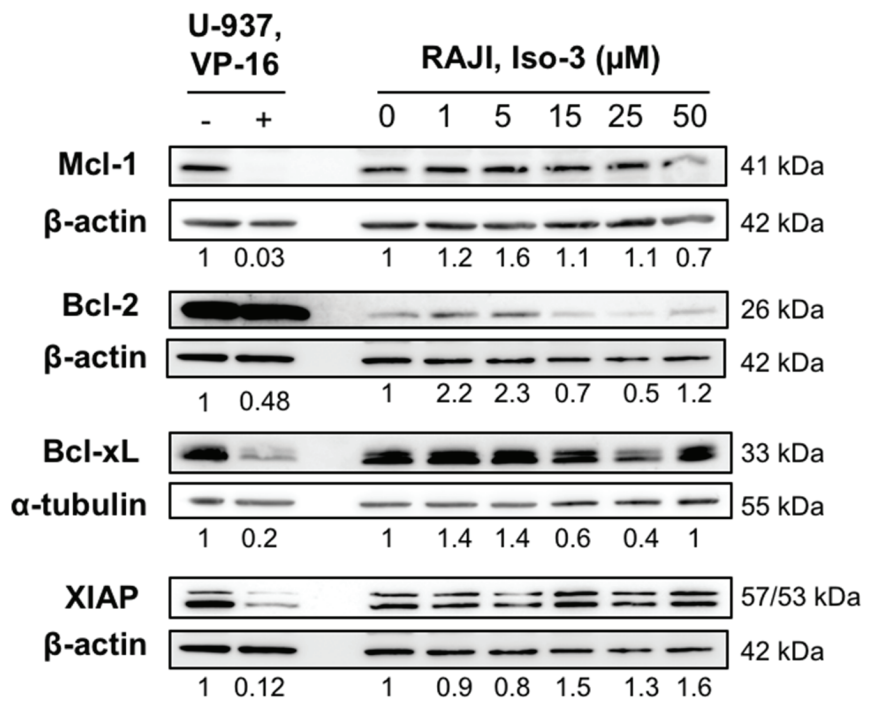

G
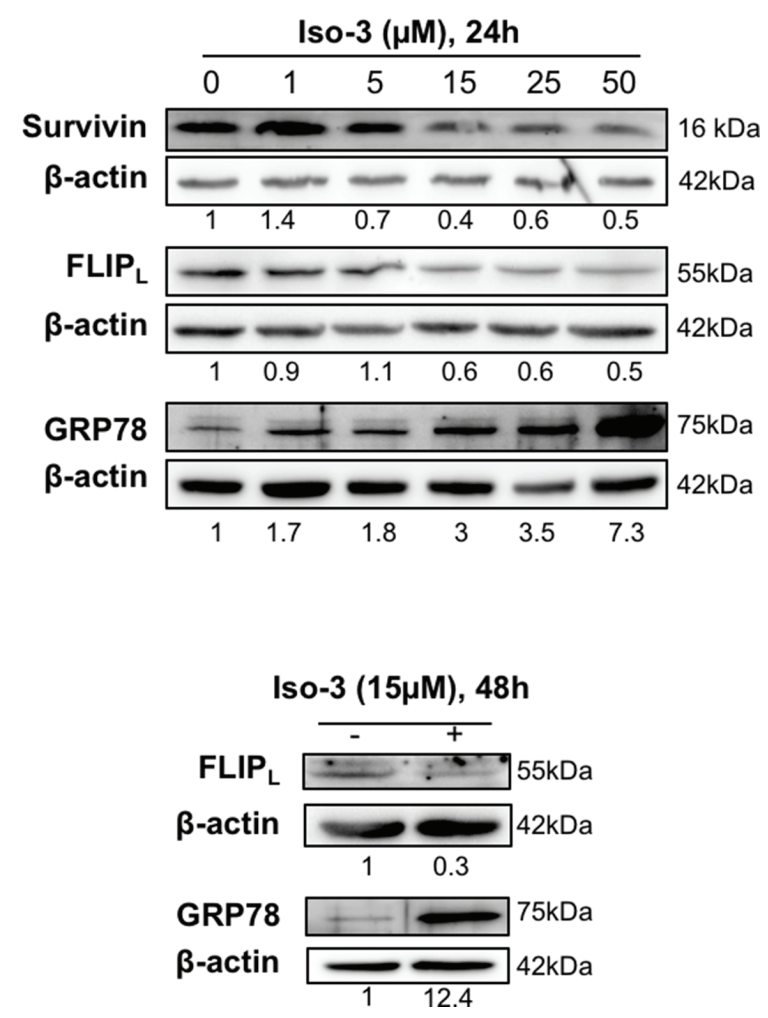

H
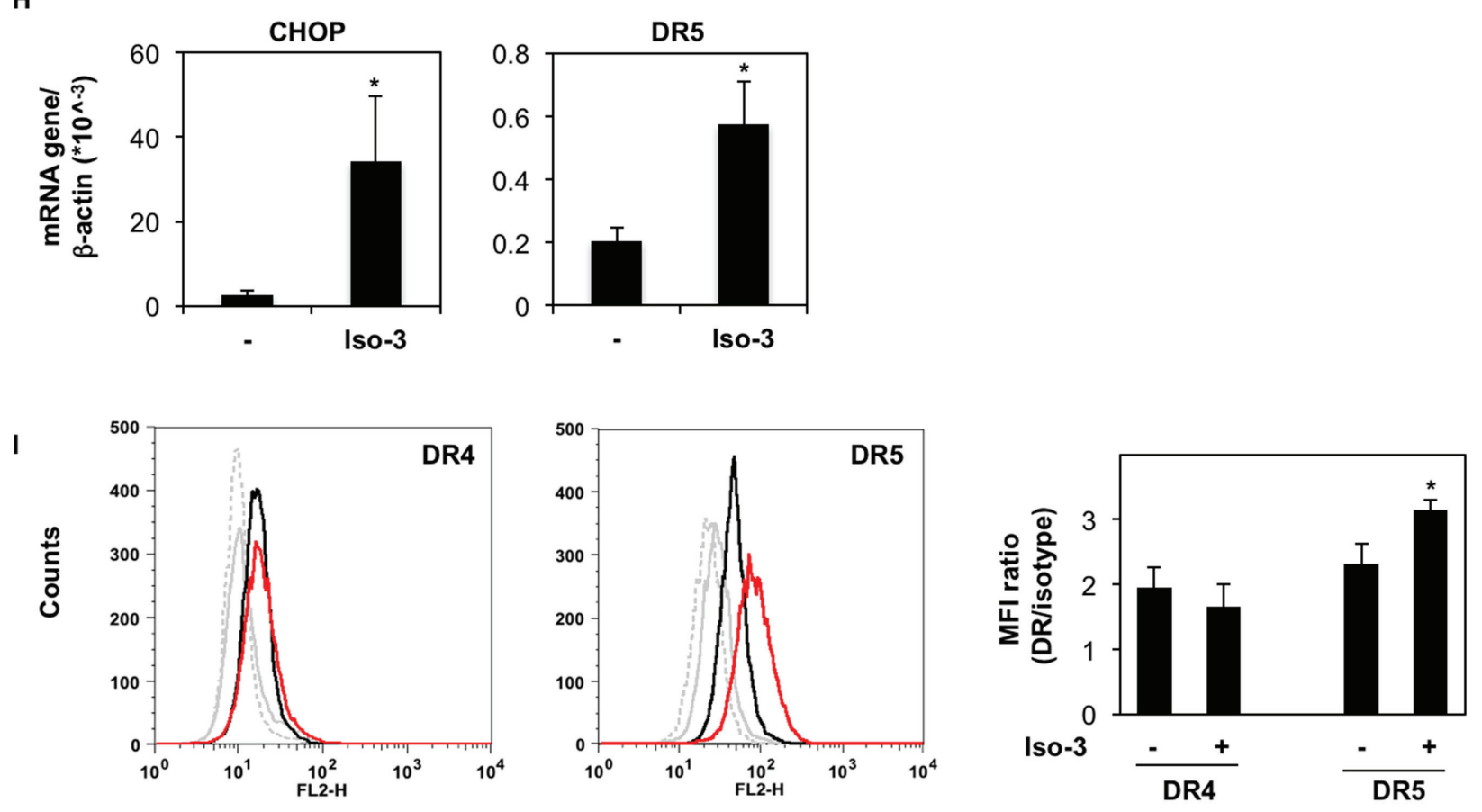

- Control, isotype

Iso-3, isotype

Control, DR

Iso-3, DR 
Figure 6: Iso-3 sensitizes cancer cells to TRAIL-induced apoptosis. (A) RAJI and U-937 cells were treated with the indicated concentrations of Iso-3 during $24 \mathrm{~h}$, then increasing concentrations of TRAIL were added for additional $24 \mathrm{~h}$ and cell viability was assessed. Significant differences between combination treatments, untreated controls and single agents are indicated with a \$. (B) Viability of RAJI cells co-treated with the indicated doses of Iso-3 and TRAIL for $48 \mathrm{~h}$. (C) Healthy donors' PBMCs were treated with Iso-3 during $24 \mathrm{~h}$, then TRAIL was added for additional $24 \mathrm{~h}$ and viability was measured. (D) RAJI and U-937 cells were treated with Iso-3 (15 $\mu \mathrm{M}$ ) and Z-VAD-FKM $(50 \mu \mathrm{M})$ for $24 \mathrm{~h}$, before TRAIL addition for $24 \mathrm{~h}(50 \mathrm{ng} / \mathrm{ml}$ for RAJI, $5 \mathrm{ng} / \mathrm{ml}$ for U-937). Cell death was measured by trypan blue exclusion assay (left panel) and Hoechst-PI staining (right panel). Significant differences between combination treatments, untreated controls and single agents are indicated with a \$; significant differences between combination treatments with and without ZVAD-FKM are indicated with a $£$. (E) Cells were treated as in panel D and caspase activation was measured by luminescent caspase 3/7 assay (right panel). Significant differences are indicated as in panel D. Western blot analysis of caspases and PARP-1 cleavage was performed in RAJI cells (left panel). $\mathrm{CF}=$ cleaved fragments. (F) Expression levels of a panel of anti-apoptotic proteins implicated in TRAIL resistance in RAJI cells after $24 \mathrm{~h}$ treatment with Iso-3. (G) Survivin, FLIP and GRP78 expression levels after $24 \mathrm{~h}$ of Iso-3 treatment (upper panel); FLIP and GRP78 levels after $48 \mathrm{~h}$ of $15 \mu \mathrm{M}$ Iso-3 treatment (lower panel) in RAJI cells. Blots are representative of three independent experiments. (H) mRNA expression levels of CHOP and DR5 in RAJI cells after treatment with $15 \mu \mathrm{M}$ Iso-3 for 48 h. (I) FACS analysis of DR4 and DR5 surface levels in RAJI cells after $48 \mathrm{~h}$ treatment with $15 \mu \mathrm{M}$ Iso-3. Representative histograms (left panel) and quantification of mean fluorescence intensity (MFI) levels (right panel) relative to matched control PE-conjugated IgG antibodies. All histograms represent the mean $\pm \mathrm{SD}$ of three independent experiments. All blots are representative of three independent experiments.

Recent work showed that hepatic AHR expression can be regulated by RNA editing mechanisms, creating miRNAs recognition sites in AHR untranslated region (UTR) [55]. We also found that AHR mRNA levels were increased by DAC and Iso-3 in neuroblastoma SH-SY5Y cells, in which AHR is known to be absent [32] by so far nondescribed mechanisms. These data suggest methylationmediated AHR repression in SH-SY5Y, similarly to RAJI cells; however, further studies on promoter methylation state in these cells are needed to validate this hypothesis. Moreover, at this point the ability of Iso-3 to affect DNA methylation at the genomic level and in other cell models remains to be investigated.

We also observed that Iso-3 reduced DNMT1 protein levels in RAJI cells, but not in other tested cell lines, whereas DAC depleted the protein in all models. These results are in agreement with a non-covalent interaction of Iso-3 with DNMT1 and suggest a post-transcriptional event leading to protein destabilization, which may occur downstream to its interaction with Iso-3, in RAJI cells. The mechanism underlying this cell line-specific degradation is still unclear; however, DNMT1 stability is regulated by the concerted action of several post-translational modifiers and depends on cell cycle progression [56]. Various levels of expression or activity of DNMT1 partners and regulators in the cell lines tested may be responsible for differential outcomes. Moreover, RAJI are latently infected with Epstein Barr virus (EBV), which was shown to modulate DNMT1 levels [57] and could play a role in Iso-3-induced DNMT1 downregulation. Altogether, we conclude here that alterations in DNMT1 expression levels are not an essential feature of Iso-3 activity, and are not required to achieve the anti-proliferative effect of the drug. Overall, the exact contribution of Iso-3 DNMT1 inhibitory activity in the anticancer effect of the drug remains to be established, and our work does not exclude that other relevant cellular targets exists and contribute to the described biological effects.
So far Iso-3 was poorly characterized with respect to its anticancer activities. In this study we showed that this marine compound displays a broad-range of antiproliferative activity against cancer cells and does not affect viability of healthy donors' PBMCs. A major tumor driver in Burkitt's lymphoma, c-myc [58], is depleted and levels of the c-myc regulated genes p21 and 27 are increased concomitantly with cell cycle arrest in RAJI cells treated by Iso-3. The cytostatic effect of Iso-3 occurs in the first place, with cell death induction appearing only at later time points and at the highest concentrations tested. In line with these features, the potential of Iso-3 to impair the replicative ability of cancer cells has been confirmed by colony formation assay and by zebrafish injection of in vitro Iso-3 treated cancer cells.

In an acute toxicity assay, Iso-3 did not reveal toxic effects against zebrafish development. The zebrafish development model has been also used to test the impact of chemicals on DNA methylation. De novo methylation of the no tail gene leads to abnormal tail development [59] and this feature is altered in response to DAC and other chemicals [60]. We did not found obvious phenotypical changes in zebrafish that could be related to Iso-3 demethylating activity after $24 \mathrm{~h}$ of treatment. Since the dynamic of de novo methylation seems to be mostly involved in development, our data may suggest that Iso3 lacks effect on de novo methyltransferases DNMT3A ad 3B. However, to exclude any effect on zebrafish development further analyses would be required, looking at specific phenotypical changes that may also occur in later stages of development, such as late hematopoiesis or specific organ developmental impairment [61, 62].

Cytostatic compounds counteract aberrant mechanisms sustaining rapid proliferation, which are mostly specific of cancer cells; thus, this class of molecules could represent a less toxic alternative to purely cytotoxic compounds. In this context, Iso- 3 is a new potential candidate for non-toxic anticancer therapy. Moreover, 
Table 2: Combination index (CI) for Iso-3 plus TRAIL treatments, in U-937 and RAJI cells

\begin{tabular}{|c|c|c|c|}
\hline Cell Line & $\begin{array}{c}\text { Concentration } \\
\text { Iso-3 }(\mu \mathrm{M})\end{array}$ & $\begin{array}{l}\text { Concentration } \\
\text { TRAIL (ng/ml) }\end{array}$ & CI \\
\hline \multirow[t]{3}{*}{ U-937 } & 5 & 1 & 0.77 \\
\hline & 15 & 2.5 & 0.43 \\
\hline & 15 & 5 & 0.21 \\
\hline \multirow[t]{3}{*}{ RAJI } & 5 & 100 & 0.36 \\
\hline & 15 & 50 & 0.22 \\
\hline & 15 & 100 & 0.21 \\
\hline
\end{tabular}

Cells were pre-treated with Iso- 3 for $24 \mathrm{~h}$ before addition of TRAIL for an additional $24 \mathrm{~h}$. CI is calculated from mean values of at least three independent trypan blue exclusion experiments.

combination therapies may take advantage of cytostatic molecules to lower the dose of cytotoxic drugs to be applied to cancer patients.

Accumulating evidence show that autophagy participates in the anticancer effect of epigenetic modulators. We previously showed that the DNA demethylating agent DAC induces autophagy in chronic myeloid leukemia [19]; recently, autophagy was implicated in the anticancer effect of zebularine, another DNA demethylating agent, against colorectal cancer cells [63]. Moreover, HDAC inhibitor treatment was shown to elicit autophagic cell death in several cancer cell models [64] and the histone methyltransferase inhibitor BIX01294 recently showed the same ability in breast cancer cells [65].

Interestingly, epigenetic drugs have been already shown to synergize with chemotherapy and some are now undergoing several clinical trials in combination treatments. In particular, both demethylating agents and HDAC inhibitors demonstrated the ability to overcome TRAIL resistance through various mechanisms [41, 42]. Importantly, pre-treatment with Iso-3 resulted in a strong sensitization of resistant cells to apoptosis induced by TRAIL. Therapeutic antibodies targeting TRAIL receptors are undergoing clinical trials and represent a very promising strategy to kill cancer cells without harming normal cells: however many cancers are resistant to these agents, and strong efforts are undergoing to find nontoxic molecules sensitizing cancer cells to TRAIL. Cell cycle arrest was previously reported to affect sensitivity of cancer cells to TRAIL [40, 66]; interestingly, we show here that only pre-treatment with Iso-3, and not concomitant treatment with Iso-3 and TRAIL, sensitizes RAJI cells to the latter, supporting a role for $\mathrm{G} 0 / \mathrm{G} 1$ arrest in sensitization. Healthy donors' PBMCs were not affected by the combination treatments, suggesting that Iso-3 could provide a non-toxic strategy to overcome TRAIL resistance. Several Burkitt's lymphoma cell lines have been previously shown to display TRAIL resistance, by a mechanism that was reported to involve impaired activation of caspase 8 [67]. In accordance, we show here that the sensitization induced by Iso-3 in RAJI cells involves re-activation of caspase 8 but not caspase 9 . Moreover, anti-apoptotic Bcl-2 family proteins and XIAP levels were not affected by Iso-3, whereas survivin levels were depleted after $24 \mathrm{~h}$ of treatment. Interestingly, besides its caspase inhibitory activity, survivin plays an important role in cell cycle progression [68]. In addition, sub-toxic concentrations of Iso-3 effectively decreased protein levels of cFLIP, a well-recognized inhibitor of caspase- 8 activation, which is frequently overexpressed in TRAIL-resistant cancer cells [69]. Concomitantly, we revealed a strong up-regulation of the ER stress induction marker GRP78. ER stress was frequently shown to restore TRAIL sensitivity by promoting, among other responses, cFLIP down-regulation $[45,46]$ and TRAIL receptor DR5 up-regulation. [47, 70-72]. In agreement with an ER stress-mediated effect, our results show that DR5 but not DR4 surface levels are increased after Iso-3 treatment. Finally, autophagy, which could result as a consequence of sustained ER stress, may also participate in the observed TRAIL sensitization, by providing a platform for DISC formation and caspase 8 activation [73]. Altogether, these data support a restoration of the extrinsic apoptotic pathway responsiveness by Iso-3, with minor or no involvement of the mitochondrial pathway, and with an ER-stress signature. The exact mechanism and the relative contribution of each player in the Iso-3-induced cancer cell sensitization to TRAIL remains to be elucidated, as well as the correlation with Iso-3 epigenetic activity, for which further investigation is guaranteed.

In conclusion, Iso-3 is a new promising agent impacting on cancer epigenetics, with a strong antiproliferative activity against cancer cell lines, and the potential to sensitize cancer cells to molecules triggering the extrinsic apoptotic pathway. 


\section{MATERIALS AND METHODS}

\section{In vitro $D N M T$ and $H D A C$ activity assays}

DNMT1 activity was measured using the in vitro DNMT activity/inhibition assay (Active Motif, Rixensart, Belgium) according to manufacturer's instructions. The methylation reaction was performed by incubating $5 \mathrm{ng}$ of purified DNMT1 for each condition with increasing concentrations of compounds for 2 hours. The methylated DNA was then recognized by the His-tagged methyl$\mathrm{CpG}$ binding domain protein $2 \mathrm{~b}$. The addition of a polyhistidine antibody conjugated to horseradish peroxidase then provided a colorimetric readout quantified with a spectrophotometer (SpectraCount, Packard) at the wavelength of $450 \mathrm{~nm}$. TritonX-100 (0.01\%) was added to the assay from a fresh dilution where indicated. For total DNMT activity assay, RAJI nuclear extracts were used as DNMT source. Total in vitro HDAC activity was measured as previously described [14].

\section{Docking studies}

Initial structures of DNMT1 were obtained from the Protein Data Bank (PDB; PDB ID: 3SWR) and coordinates for the sinefungin, Iso-3, aerothionin, and bisoxasolidinone were generated using the GlycoBioChem PRODRG2 Server [74]. After removing ligands and DNA in the original data, we operated the PatchDock program $[22,74]$ with protein and compound as receptor and ligand, respectively. Structural superposition of 3PTA and 3SWR coordinates was performed using WinCoot [66].

\section{Cell culture and reagents}

RAJI (Burkitt's lymphoma), U-937 (non-Hodgkin lymphoma), JURKAT (ALL), K-562 (chronic myeloid leukemia, CML), HL-60 (promyelocytic leukemia) MEG-01 (CML in megakaryocytic blast crisis), PC-3 (prostate cancer) cells were obtained from the Deutsche Sammlung von Mikroorganismen und Zellkulturen $\mathrm{GmbH}$ (Braunschweig, Germany). SH-SY5Y (neuroblastoma) and MDA-MB-231 (breast adenocarcinoma) were obtained from the American tissue culture collection (Manassas, VA, USA). All cell lines were cultured in RPMI 1640 medium (Lonza, Verviers, Belgium) supplemented with $10 \%$ heat-inactivated fetal calf serum (Lonza) and 1\% antibiotic-antimycotic (Lonza). Peripheral blood mononuclear cells (PBMCs) from human healthy donors were isolated and cultured as previously described [19]. All experiments were performed on cells in the exponential growth phase. Iso-3 was purified from Aplysina aerophoba [17] and dissolved in DMSO. Epigallocatechin gallate (EGCG), DAC, Necrostatin-1,
VP-16, PP242 and bafilomycin $A_{1}$ were purchased from Sigma-Aldrich (Bornem, Belgium). SAHA and Z-VAD-FKM were purchased from Cayman Bio-connect (Huissen, The Netherlands) and from Millipore (Merck, Brussels, Belgium), respectively. All drugs were dissolved in DMSO. Recombinant human TRAIL was purchased by Enzo Life Science (Antwerpen, Belgium).

\section{mRNA expression analysis}

Gene expression analyses were performed by real-time RT-PCR as previously described [75]. Primer sequences are available on request.

\section{CpG methylation analysis}

Bisulfite cloning and sequencing was performed as previously described [76]. Briefly, BSP primers specific for AHR (NCBI accession number NC_000007.14) were designed with Methylprimer express software (Applied Biosystems, Halle, Belgium). $\mathrm{CpG}$ island search was performed with the following parameters: a minimum length of 300 nucleotide, minimum $\mathrm{G}+\mathrm{C}$ content of $50 \%$, observed/expected $\mathrm{CpG}$ ratio of 0.6. A 1489-nt fragment was identified, containing a $\mathrm{CpG}$ island and the transcription start site. Within this fragment, a 320-nucleotide region was selected for further analysis. Bisulfite-modified genomic DNA was amplified with specific primers (FW: 5'-GGGTGGGGTTTTTAAGGA3'; REV: 5'-CTTCCTAAATCCAAAATACTTCC-3') and the Hot start TaqTM polymerase (Qiagen, Venlo, The Netherlands). Thermal conditions were $15 \mathrm{~min}$ at $95^{\circ} \mathrm{C}$, 40 cycles of $94^{\circ} \mathrm{C}$ for $1 \mathrm{~min}, 58^{\circ} \mathrm{C}$ for $1 \mathrm{~min}, 72^{\circ} \mathrm{C}$ for $1 \mathrm{~min}$, and a final extension step of $10 \mathrm{~min}$ at $72^{\circ} \mathrm{C}$. PCR products were separated on agarose gels, purified with the Qiaquick Gel extraction Kit (Qiagen), cloned into pCR2.1-TOPO vector (Invitrogen, Tournai, Belgium). Plasmids were purified with Qiaprep Spin miniprep kit (Qiagen) and sequenced (GATC Biotech, Konstanz, Germany). Methylation analysis was performed by QUMA software [77].

\section{Cell proliferation and viability assays}

Cell proliferation and viability were measured by using the trypan blue exclusion assay (Lonza, Verviers, Belgium). The number of cells per $\mathrm{ml}$ was counted and the fraction of trypan blue-positive cells was estimated by using a Cedex cell counter (Innovatis AG, Roche, Luxembourg, Luxembourg). For colony formation assays, cells $\left(10^{3}\right.$ cells $\left./ \mathrm{ml}\right)$ were grown in semi solid methylcellulose medium (Methocult H4230, StemCell Technologies Inc., Vancouver, Canada) supplemented with the indicated Iso-3 concentrations. 
Colonies were detected after 10 days of culture by adding $1 \mathrm{mg} / \mathrm{ml}$ of 3-(4,5-dimethylthiazol-2-yl)-2,5diphenyltetrazoliumbromide (MTT) reagent (Sigma) and were scored by Image J software (U.S. National Institute of Health, Bethesda, MD, USA).

\section{Evaluation of apoptosis}

The percentage of apoptotic cells was quantified as the fraction of cells showing apoptotic, fragmented nuclei, as assessed by fluorescence microscopy (LeicaDM IRB microscope, Lecuit, Howald, Luxembourg) after staining with Hoechst 33342 and PI. Enzymatic activity of caspases-3/7 was determined using the Caspase-Glo 3/7 Assay (Promega, Leiden, The Netherlands). The assay was performed according to the manufacturer's instructions and luminescence was measured using an Orion Microplate Luminometer (Berthold, Pforzheim, Germany).

\section{Cell cycle distribution and size/granularity analyses}

For cell cycle analysis, cells were collected and fixed in ethanol $70 \%$. DNA was stained with a PI solution ( $1 \mu \mathrm{g} / \mathrm{ml}$, Sigma-Aldrich) in 1x PBS, supplemented with RNase A (100 $\mu \mathrm{g} / \mathrm{ml}$; Roche). Samples were analyzed by flow cytometry (FACS Calibur, Becton Dickinson (BD) Biosciences, San Jose, CA, USA). Relative cell size and granularity were evaluated based on forward (FSC) and side (SSC) scatter parameters assessed by flow cytometry. Data were recorded statistically (10,000 events/sample) using the CellQuest software (BD Biosciences) and analyzed using Flow-Jo 8.8.5 software (Tree Star, Inc., Ashland, OR, USA).

\section{Protein extraction and western blotting}

Whole cell extracts were prepared using M-PER ${ }^{\circledR}$ (Thermofisher, Erembodegen, Belgium) supplemented by $1 x$ protease inhibitor cocktail (Complete EDTA-free, Roche, Prophac, Luxembourg, Luxembourg) according to manufacturer's instructions. Histone enrichment was performed as previously described [14]. Western blots were performed using the following primary antibodies: anti-DNMT3A (3598), anti-caspase 7 (9494S), anticaspase 9 (9502S), anti-caspase 8 (9746), anti-PARP (9542), anti-Mcl-1 (4572S), anti-cyclin E1 (4129) from Cell Signaling (Leiden, The Netherlands); antiDNMT1 (sc-10222), anti-caspase 3 (sc-56053), anti-p21 (sc-817), anti-p27 (sc-527), anti-PCNA (sc-9857R), anti-GRP78 (13968), anti-AHR (8088) from Santa Cruz Biotechnology (Boechout, Belgium); anti-c-myc (51-1485GR), anti-Bcl-xL (610212), anti-XIAP (610763) from BD Pharmigen (Erembodegem, Belgium); anti-FLIP (804-961) from Enzo Life Science, anti-DNMT3B (2851) from Abcam (Cambridge, UK); anti-acetylated histone H4 (06-866), anti-histone H1 (05-457), anti Bcl-2 (OP60) and anti-alpha tubulin (CP06) from Millipore; anti LC-3 (L7543) and anti-beta actin (5441) from Sigma Aldrich; anti-survivin (AF886) from R \& D System (Abingdon, UK). Bands were quantified using ImageQuant TL (GE Healthcare, Buckinghamshire, UK) and values of fold change are reported underneath western blots.

\section{Morphological analysis}

Cells $\left(3 \times 10^{5}\right)$ were washed in $1 \times$ PBS and spun onto a glass slide using a Shandon Cytospin 4 (Thermofisher), fixed and stained with the Diff-Quick stain kit (Dade Behring S.A., Brussels, Belgium) according to the manufacturer' $s$ procedure. Images were acquired using a Leica DM2000 equipped with a DFC420C camera and Leica FireCam software.

\section{Analyses of autophagic vesicles}

Samples for transmission electron microscopy analysis were prepared and observed as previously described [19]. Current guidelines for the analysis of cellular structures were followed for interpretation [39]. For fluorescence microscopy analysis, $1 \times 10^{6}$ cells were stained with Cyto-ID ${ }^{\circledR}$ Green dye and Hoechst 33342, according to manufacturer's instructions (Enzo Life Science). Cells were observed by fluorescence microscopy analysis using an IX81(MT10) Olympus microscope (Olympus, Aartselaar, Belgium).

\section{Zebrafish toxicity assay and cancer cell xenografts}

Wild type zebrafish (Danio rerio) were obtained from the Zebrafish International Resource Center (ZIRC, University of Oregon, OR), maintained according SNU guidelines at $28.5^{\circ} \mathrm{C}$ with $10 \mathrm{hr}$ dark/14 hr light cycles. For toxicity assays, embryos were treated with $0.003 \%$ phenylthiourea $14 \mathrm{hr}$ before the assay in order to remove pigmentation. Two hr before the assay, the embryo's shell was eliminated and then treated for up to $24 \mathrm{hr}$ with Iso3 at indicated concentrations in 24 well plates. Ethanol (3\%) was used as a positive control for toxicity. Viability and abnormal development were assessed after $24 \mathrm{hr}$ of treatment under light microscopy (Carl Zeiss Stereo microscope DV4, Seoul, Korea). Pictures were taken by fixing zebrafish embryos onto a glass slide with 3\% methylcellulose (Sigma Aldrich). For cancer xenograft assays, after mating, fertilized eggs were incubated in Danieau's solution with $0.003 \%$ of phenylthiourea (PTU) at $28.5^{\circ} \mathrm{C}$ for $48 \mathrm{hr}$. Micropipettes for injection and anesthesia were generated from a $1.0 \mathrm{~mm}$ glass capillary (World Precision Instruments, FL, USA) by using a micropipette puller (Shutter Instrument, USA). 48 hours post fertilization (hpf), 
zebrafish were anesthetized in $0.02 \%$ tricaine (Sigma, MO) and immobilized on an agar plate. 100-200 of VampiroPC3 or Vampiro-SH-SY5Y cells (Innoprot, Spain), with and without Iso-3 pretreatment at indicated concentrations for $24 \mathrm{hr}$, were injected into the yolk sac by microinjection (PV820 microinjector, World Precision Instruments, FL, USA). Subsequently, zebrafish were incubated in 96well plates containing Danieau's solution with $0.003 \%$ phenylthiourea (PTU) at $28.5^{\circ} \mathrm{C}$ for $72 \mathrm{hr}$. Fishes were then immobilized in a drop of $3 \%$ methylcellulose in Danieau's solution on a glass slide. Pictures were taken by fluorescence microscopy (Leica DE/DM 5000B). Area of fluorescent tumors was quantified by Image J software (http://rsb.info.nih.gov/ij/docs/index.html).

\section{Analysis of cell surface expression of DR4 and DR5}

Control and treated RAJI cells $\left(1 \times 10^{6}\right)$ were stained with phycoerythrin (PE)-conjugated mouse monoclonal anti-human DR4 and DR5 antibodies (R \& D system) or matched PE-conjugated mouse IgG, for $1 \mathrm{~h}$ at $4^{\circ} \mathrm{C}$. Cells were then resuspended in $1 \times$ PBS and analyzed by flow cytometry. Data were analyzed by using Flow-Jo 8.8.5 software (Treestar, Ashland, OR, USA).

\section{Statistics}

Significant differences were determined using the Student's $t$-test or the Fisher exact test (for methylation data). Statistical significances were evaluated at $p$-values below 0.05 and represented by the following legend: $* p \leq 0.05, * * p \leq 0.001$. Growth inhibitory dose $50 \%$ $\left(\mathrm{GI}_{50}\right)$ calculation was performed with Prism software. Combination index (CI) was calculated according to Chou and Talalay [43] using Compusyn Software (ComboSyn, Inc., Paramus, NJ, USA). CI values below 1 indicate synergism. All histograms represent the mean $\pm \mathrm{SD}$ of at least 3 independent experiments.

\section{ACKNOWLEDGMENTS}

The authors thank Justine Paoli for technical assistance with electron microscopy.

\section{FUNDING}

CF was supported by the «Ministère de la Culture, de l'Enseignement supérieur et de la Recherche du Luxembourg» and by Télévie Luxembourg. MS is supported by a "Waxweiler grant for cancer prevention research" from the Action Lions "Vaincre le Cancer". CG is supported by Télévie Luxembourg. This work was supported by Télévie Luxembourg, the «Recherche Cancer et Sang» foundation and «Recherches Scientifiques
Luxembourg» association. The authors thank «Een Häerz fir Kriibskrank Kanner» association and the Action Lions "Vaincre le Cancer" for generous support. Further support was received from the European Union (ITN "RedCat" 215009 and Interreg IVa project "Corena"). MD was supported by a grant from Research Institute of Pharmaceutical Sciences, College of Pharmacy, Seoul National University, by the NRF by the MEST of Korea for Tumor Microenvironment GCRC 2012-0001184 grant and by Brain Korea (BK21) PLUS program.

\section{CONFLICTS OF INTEREST}

The authors declare no conflicts of interest.

\section{REFERENCES}

1. Schnekenburger M, Florean C, Dicato M, Diederich M. Epigenetic alterations as a universal feature of cancer hallmarks and a promising target for personalized treatments. Curr Top Med Chem. 2016; 16:745-776.

2. Florean C, Schnekenburger M, Grandjenette C, Dicato M, Diederich M. Epigenomics of leukemia: from mechanisms to therapeutic applications. Epigenomics. 2011; 3:581-609.

3. Schnekenburger M, Diederich M. Epigenetics Offer New Horizons for Colorectal Cancer Prevention. Curr Colorectal Cancer Rep. 2012; 8:66-81.

4. Seidel C, Florean C, Schnekenburger M, Dicato M, Diederich M. Chromatin-modifying agents in anti-cancer therapy. Biochimie. 2012; 94:2264-2279.

5. Yoo CB, Jones PA. Epigenetic therapy of cancer: past, present and future. Nat Rev Drug Discov. 2006; 5:37-50. doi: 10.18632/oncotarget.2624.

6. Schnekenburger M, Dicato M, Diederich M. Plant-derived epigenetic modulators for cancer treatment and prevention. Biotechnol Adv. 2014; 32:1123-1132.

7. Schnekenburger M, Dicato M, Diederich M. Epigenetic modulators from "The Big Blue": a treasure to fight against cancer. Cancer Lett. 2014; 351:182-197.

8. Gros C, Fahy J, Halby L, Dufau I, Erdmann A, Gregoire JM, Ausseil F, Vispe S, Arimondo PB. DNA methylation inhibitors in cancer: recent and future approaches. Biochimie. 2012; 94:2280-2296.

9. Mayer AM, Gustafson KR. Marine pharmacology in 2000: antitumor and cytotoxic compounds. Int J Cancer. 2003; 105:291-299.

10. Essack M, Bajic VB, Archer JA. Recently confirmed apoptosis-inducing lead compounds isolated from marine sponge of potential relevance in cancer treatment. Mar Drugs. 2011; 9:1580-1606.

11. Schwartsmann G, Brondani da Rocha A, Berlinck RG, Jimeno J. Marine organisms as a source of new anticancer agents. Lancet Oncol. 2001; 2:221-225. 
12. Pereira R, Benedetti R, Perez-Rodriguez S, Nebbioso A, Garcia-Rodriguez J, Carafa V, Stuhldreier M, Conte M, Rodriguez-Barrios F, Stunnenberg HG, Gronemeyer H, Altucci L, de Lera AR. Indole-derived psammaplin A analogues as epigenetic modulators with multiple inhibitory activities. J Med Chem. 2012; 55:9467-9491.

13. Pina IC, Gautschi JT, Wang GY, Sanders ML, Schmitz FJ, France D, Cornell-Kennon S, Sambucetti LC, Remiszewski SW, Perez LB, Bair KW, Crews P. Psammaplins from the sponge Pseudoceratina purpurea: inhibition of both histone deacetylase and DNA methyltransferase. J Org Chem. 2003; 68:3866-3873.

14. Seidel C, Schnekenburger M, Dicato M, Diederich M. Antiproliferative and proapoptotic activities of 4-hydroxybenzoic acid-based inhibitors of histone deacetylases. Cancer Lett. 2014; 343:134-146.

15. Baud MG, Leiser T, Haus P, Samlal S, Wong AC, Wood RJ, Petrucci V, Gunaratnam M, Hughes SM, Buluwela L, Turlais F, Neidle S, Meyer-Almes FJ, et al. Defining the mechanism of action and enzymatic selectivity of psammaplin A against its epigenetic targets. J Med Chem. 2012; 55:1731-1750.

16. Baud MG, Leiser T, Petrucci V, Gunaratnam M, Neidle S, Meyer-Almes FJ, Fuchter MJ. Thioester derivatives of the natural product psammaplin A as potent histone deacetylase inhibitors. Beilstein J Org Chem. 2013; 9:81-88.

17. Teeyapant R, Woerdenbag HJ, Kreis P, Hacker J, Wray V, Witte L, Proksch P. Antibiotic and cytotoxic activity of brominated compounds from the marine sponge Verongia aerophoba. Z Naturforsch C. 1993; 48:939-945.

18. Mijares MR, Ochoa M, Barroeta A, Martinez GP, Suarez AI, Compagnone RS, Chirinos P, Avila R, De Sanctis JB. Cytotoxic effects of Fisturalin-3 and 11-Deoxyfisturalin-3 on Jurkat and U937 cell lines. Biomed Pap Med Fac Univ Palacky Olomouc Czech Repub. 2013; 157:222-226.

19. Schnekenburger M, Grandjenette C, Ghelfi J, Karius T, Foliguet B, Dicato M, Diederich M. Sustained exposure to the DNA demethylating agent, 2'-deoxy-5-azacytidine, leads to apoptotic cell death in chronic myeloid leukemia by promoting differentiation, senescence, and autophagy. Biochem Pharmacol. 2011; 81:364-378.

20. Bose P, Dai Y, Grant S. Histone deacetylase inhibitor (HDACI) mechanisms of action: emerging insights. Pharmacol Ther. 2014; 143:323-336. doi: 10.18632/ oncotarget.1426.

21. Feng BY, Shoichet BK. A detergent-based assay for the detection of promiscuous inhibitors. Nat Protoc. 2006; 1:550-553.

22. Duhovny D, Nussinov R, Wolfson H. Efficient Unbound Docking of Rigid Molecules. In: Guigó R, Gusfield D, eds. Algorithms in Bioinformatics: Springer Berlin Heidelberg. 2002; 185-200.

23. Schneidman-Duhovny D, Inbar Y, Nussinov R, Wolfson HJ. PatchDock and SymmDock: servers for rigid and symmetric docking. Nucleic Acids Res. 2005; 33:W363-367.
24. Song J, Rechkoblit O, Bestor TH, Patel DJ. Structure of DNMT1-DNA complex reveals a role for autoinhibition in maintenance DNA methylation. Science. 2011; 331: 1036-1040.

25. Fan Y, Boivin GP, Knudsen ES, Nebert DW, Xia Y, Puga A. The aryl hydrocarbon receptor functions as a tumor suppressor of liver carcinogenesis. Cancer Res. 2010; 70:212-220.

26. Fritz WA, Lin TM, Cardiff RD, Peterson RE. The aryl hydrocarbon receptor inhibits prostate carcinogenesis in TRAMP mice. Carcinogenesis. 2007; 28:497-505.

27. Murray IA, Patterson AD, Perdew GH. Aryl hydrocarbon receptor ligands in cancer: friend and foe. Nat Rev Cancer. 2014; 14:801-814.

28. Mulero-Navarro S, Carvajal-Gonzalez JM, Herranz M, Ballestar E, Fraga MF, Ropero S, Esteller M, FernandezSalguero PM. The dioxin receptor is silenced by promoter hypermethylation in human acute lymphoblastic leukemia through inhibition of Sp1 binding. Carcinogenesis. 2006; 27:1099-1104.

29. Zhu WG, Srinivasan K, Dai Z, Duan W, Druhan LJ, Ding H, Yee L, Villalona-Calero MA, Plass C, Otterson GA. Methylation of adjacent $\mathrm{CpG}$ sites affects $\mathrm{Sp} 1 / \mathrm{Sp} 3$ binding and activity in the p21(Cip1) promoter. Mol Cell Biol. 2003; 23:4056-4065.

30. Mudduluru G, Allgayer $\mathrm{H}$. The human receptor tyrosine kinase Axl gene-promoter characterization and regulation of constitutive expression by $\mathrm{Sp} 1, \mathrm{Sp} 3$ and $\mathrm{CpG}$ methylation. Biosci Rep. 2008; 28:161-176.

31. Kitazawa S, Kitazawa R, Maeda S. Transcriptional regulation of rat cyclin $\mathrm{D} 1$ gene by $\mathrm{CpG}$ methylation status in promoter region. J Biol Chem. 1999; 274:28787-28793. doi: 10.18632/oncotarget.2029.

32. Imran S, Ferretti P, Vrzal R. Different regulation of aryl hydrocarbon receptor-regulated genes in response to dioxin in undifferentiated and neuronally differentiated human neuroblastoma SH-SY5Y cells. Toxicol Mech Methods. 2015; 25:689-697.

33. Thottassery JV, Sambandam V, Allan PW, Maddry JA, Maxuitenko YY, Tiwari K, Hollingshead M, Parker WB. Novel DNA methyltransferase-1 (DNMT1) depleting anticancer nucleosides, 4'-thio-2'-deoxycytidine and 5-aza4'-thio-2'-deoxycytidine. Cancer Chemother Pharmacol. 2014; 74:291-302.

34. Majid S, Dar AA, Ahmad AE, Hirata H, Kawakami K, Shahryari V, Saini S, Tanaka Y, Dahiya AV, Khatri G, Dahiya R. BTG3 tumor suppressor gene promoter demethylation, histone modification and cell cycle arrest by genistein in renal cancer. Carcinogenesis. 2009; 30:662-670.

35. Liu Z, Liu S, Xie Z, Pavlovicz RE, Wu J, Chen P, Aimiuwu J, Pang J, Bhasin D, Neviani P, Fuchs JR, Plass $\mathrm{C}$, Li PK, et al. Modulation of DNA methylation by a sesquiterpene lactone parthenolide. J Pharmacol Exp Ther. 2009; 329:505-514. 
36. Fu LJ, Ding YB, Wu LX, Wen CJ, Qu Q, Zhang X, Zhou HH. The Effects of Lycopene on the Methylation of the GSTP1 Promoter and Global Methylation in Prostatic Cancer Cell Lines PC3 and LNCaP. Int J Endocrinol. 2014; 2014:620165.

37. Datta J, Ghoshal K, Denny WA, Gamage SA, Brooke DG, Phiasivongsa P, Redkar S, Jacob ST. A new class of quinoline-based DNA hypomethylating agents reactivates tumor suppressor genes by blocking DNA methyltransferase 1 activity and inducing its degradation. Cancer Res. 2009; 69:4277-4285.

38. Andrade AF, Borges KS, Castro-Gamero AM, Silveira VS, Suazo VK, Oliveira JC, Moreno DA, de Paula Queiroz RG, Scrideli CA, Tone LG. Zebularine induces chemosensitization to methotrexate and efficiently decreases AhR gene methylation in childhood acute lymphoblastic leukemia cells. Anticancer Drugs. 2014; 25:72-81.

39. Klionsky DJ, Abdalla FC, Abeliovich H, Abraham RT, Acevedo-Arozena A, Adeli K, Agholme L, Agnello M, Agostinis P, Aguirre-Ghiso JA, Ahn HJ, Ait-Mohamed O, Ait-Si-Ali S, et al. Guidelines for the use and interpretation of assays for monitoring autophagy. Autophagy. 2012; 8:445-544.

40. Jin Z, Dicker DT, El-Deiry WS. Enhanced sensitivity of G1 arrested human cancer cells suggests a novel therapeutic strategy using a combination of simvastatin and TRAIL. Cell Cycle. 2002; 1:82-89.

41. Eramo A, Pallini R, Lotti F, Sette G, Patti M, Bartucci M, Ricci-Vitiani L, Signore M, Stassi G, Larocca LM, Crino L, Peschle C, De Maria R. Inhibition of DNA methylation sensitizes glioblastoma for tumor necrosis factor-related apoptosis-inducing ligand-mediated destruction. Cancer Res. 2005; 65:11469-11477.

42. Fulda S. Histone deacetylase (HDAC) inhibitors and regulation of TRAIL-induced apoptosis. Exp Cell Res. 2012; 318:1208-1212.

43. Chou TC. Drug combination studies and their synergy quantification using the Chou-Talalay method. Cancer Res. 2010; 70:440-446.

44. Dimberg LY, Anderson CK, Camidge R, Behbakht K, Thorburn A, Ford HL. On the TRAIL to successful cancer therapy? Predicting and counteracting resistance against TRAIL-based therapeutics. Oncogene. 2013; 32: 1341-1350.

45. Martin-Perez R, Niwa M, Lopez-Rivas A. ER stress sensitizes cells to TRAIL through down-regulation of FLIP and Mcl-1 and PERK-dependent up-regulation of TRAIL-R2. Apoptosis. 2012; 17:349-363.

46. Tiwary R, Yu W, Li J, Park SK, Sanders BG, Kline K. Role of endoplasmic reticulum stress in alpha-TEA mediated TRAIL/DR5 death receptor dependent apoptosis. PLoS One. 2010; 5:e11865.
47. Trivedi R, Mishra DP. Trailing TRAIL Resistance: Novel Targets for TRAIL Sensitization in Cancer Cells. Front Oncol. 2015; 5:69.

48. Fagan RL, Cryderman DE, Kopelovich L, Wallrath LL, Brenner C. Laccaic acid A is a direct, DNA-competitive inhibitor of DNA methyltransferase 1. J Biol Chem. 2013; 288:23858-23867.

49. Marlowe JL, Puga A. Aryl hydrocarbon receptor, cell cycle regulation, toxicity, and tumorigenesis. J Cell Biochem. 2005; 96:1174-1184.

50. Sartor MA, Schnekenburger M, Marlowe JL, Reichard JF, Wang Y, Fan Y, Ma C, Karyala S, Halbleib D, Liu X, Medvedovic M, Puga A. Genomewide analysis of aryl hydrocarbon receptor binding targets reveals an extensive array of gene clusters that control morphogenetic and developmental programs. Environ Health Perspect. 2009; 117:1139-1146.

51. Salomon-Nguyen F, Della-Valle V, Mauchauffe M, BussonLe Coniat M, Ghysdael J, Berger R, Bernard OA. The $\mathrm{t}(1 ; 12)(\mathrm{q} 21 ; \mathrm{p} 13)$ translocation of human acute myeloblastic leukemia results in a TEL-ARNT fusion. Proc Natl Acad Sci U S A. 2000; 97:6757-6762.

52. Englert NA, Turesky RJ, Han W, Bessette EE, Spivack SD, Caggana M, Spink DC, Spink BC. Genetic and epigenetic regulation of AHR gene expression in $\mathrm{MCF}-7$ breast cancer cells: role of the proximal promoter GC-rich region. Biochem Pharmacol. 2012; 84:722-735.

53. Fukushima-Uesaka H, Sai K, Maekawa K, Koyano S, Kaniwa N, Ozawa S, Kawamoto M, Kamatani N, Komamura K, Kamakura S, Kitakaze M, Tomoike H, Ueno K, et al. Genetic variations of the AHR gene encoding aryl hydrocarbon receptor in a Japanese population. Drug Metab Pharmacokinet. 2004; 19:320-326.

54. Li D, Takao T, Tsunematsu R, Morokuma S, Fukushima K, Kobayashi H, Saito T, Furue M, Wake N, Asanoma K. Inhibition of AHR transcription by NF1C is affected by a single-nucleotide polymorphism, and is involved in suppression of human uterine endometrial cancer. Oncogene. 2013; 32:4950-4959.

55. Nakano M, Fukami T, Gotoh S, Takamiya M, Aoki Y, Nakajima M. RNA Editing Modulates Human Hepatic Aryl Hydrocarbon Receptor Expression by Creating MicroRNA Recognition Sequence. J Biol Chem. 2016; 291:894-903.

56. Kar S, Deb M, Sengupta D, Shilpi A, Parbin S, Torrisani J, Pradhan S, Patra S. An insight into the various regulatory mechanisms modulating human DNA methyltransferase 1 stability and function. Epigenetics. 2012; 7:994-1007.

57. Leonard S, Wei W, Anderton J, Vockerodt M, Rowe M, Murray PG, Woodman CB. Epigenetic and transcriptional changes which follow Epstein-Barr virus infection of germinal center B cells and their relevance to the pathogenesis of Hodgkin's lymphoma. J Virol. 2011; 85:9568-9577. 
58. Ott G, Rosenwald A, Campo E. Understanding MYCdriven aggressive B-cell lymphomas: pathogenesis and classification. Blood. 2013; 122:3884-3891.

59. Yamakoshi K, Shimoda N. De novo DNA methylation at the $\mathrm{CpG}$ island of the zebrafish no tail gene. Genesis. 2003; 37:195-202.

60. Ceccaldi A, Rajavelu A, Champion C, Rampon C, Jurkowska R, Jankevicius G, Senamaud-Beaufort C, Ponger L, Gagey N, Ali HD, Tost J, Vriz S, Ros S, et al. C5-DNA methyltransferase inhibitors: from screening to effects on zebrafish embryo development. Chembiochem. $2011 ; 12: 1337-1345$.

61. Liu X, Jia X, Yuan H, Ma K, Chen Y, Jin Y, Deng M, Pan W, Chen S, Chen Z, de The H, Zon LI, Zhou Y, et al. DNA methyltransferase 1 functions through $\mathrm{C} /$ ebpa to maintain hematopoietic stem and progenitor cells in zebrafish. J Hematol Oncol. 2015; 8:15.

62. Takayama K, Shimoda N, Takanaga S, Hozumi S, Kikuchi Y. Expression patterns of dnmt3aa, dnmt3ab, and dnmt4 during development and fin regeneration in zebrafish. Gene Expr Patterns. 2014; 14:105-110.

63. Yang PM, Lin YT, Shun CT, Lin SH, Wei TT, Chuang SH, Wu MS, Chen CC. Zebularine inhibits tumorigenesis and stemness of colorectal cancer via p53-dependent endoplasmic reticulum stress. Sci Rep. 2013; 3:3219.

64. Zhang J, Zhong Q. Histone deacetylase inhibitors and cell death. Cell Mol Life Sci. 2014; 71:3885-3901.

65. Kim Y, Kim YS, Kim DE, Lee JS, Song JH, Kim HG, Cho DH, Jeong SY, Jin DH, Jang SJ, Seol HS, Suh YA, Lee SJ, et al. BIX-01294 induces autophagy-associated cell death via EHMT2/G9a dysfunction and intracellular reactive oxygen species production. Autophagy. 2013; 9:2126-2139.

66. Ehrhardt H, Wachter F, Grunert M, Jeremias I. Cell cyclearrested tumor cells exhibit increased sensitivity towards TRAIL-induced apoptosis. Cell Death Dis. 2013; 4:e661.

67. Kang J, Kisenge RR, Toyoda H, Tanaka S, Bu J, Azuma E, Komada Y. Chemical sensitization and regulation of TRAIL-induced apoptosis in a panel of B-lymphocytic leukaemia cell lines. Br J Haematol. 2003; 123:921-932.

68. Athanasoula K, Gogas H, Polonifi K, Vaiopoulos AG, Polyzos A, Mantzourani M. Survivin beyond physiology: orchestration of multistep carcinogenesis and therapeutic potentials. Cancer Lett. 2014; 347:175-182.

69. Safa AR, Pollok KE. Targeting the Anti-Apoptotic Protein c-FLIP for Cancer Therapy. Cancers (Basel). 2011; 3: 1639-1671.
70. Jiang CC, Chen LH, Gillespie S, Kiejda KA, Mhaidat N, Wang YF, Thorne R, Zhang XD, Hersey P. Tunicamycin sensitizes human melanoma cells to tumor necrosis factorrelated apoptosis-inducing ligand-induced apoptosis by upregulation of TRAIL-R2 via the unfolded protein response. Cancer Res. 2007; 67:5880-5888.

71. $\mathrm{Lu} \mathrm{M}$, Lawrence DA, Marsters S, Acosta-Alvear D, Kimmig P, Mendez AS, Paton AW, Paton JC, Walter P, Ashkenazi A. Cell death. Opposing unfolded-proteinresponse signals converge on death receptor 5 to control apoptosis. Science. 2014; 345:98-101.

72. Yoon MJ, Kang YJ, Kim IY, Kim EH, Lee JA, Lim JH, Kwon TK, Choi KS. Monensin, a polyether ionophore antibiotic, overcomes TRAIL resistance in glioma cells via endoplasmic reticulum stress, DR5 upregulation and c-FLIP downregulation. Carcinogenesis. 2013; 34:1918-1928.

73. Young MM, Takahashi Y, Khan O, Park S, Hori T, Yun J, Sharma AK, Amin S, Hu CD, Zhang J, Kester M, Wang HG. Autophagosomal membrane serves as platform for intracellular death-inducing signaling complex (iDISC)mediated caspase- 8 activation and apoptosis. J Biol Chem. 2012; 287:12455-12468.

74. Schuttelkopf AW, van Aalten DM. PRODRG: a tool for high-throughput crystallography of protein-ligand complexes. Acta Crystallogr D Biol Crystallogr. 2004; 60:1355-1363.

75. Grandjenette C, Schnekenburger M, Karius T, Ghelfi J, Gaigneaux A, Henry E, Dicato M, Diederich M. 5-aza-2'deoxycytidine-mediated c-myc Down-regulation triggers telomere-dependent senescence by regulating human telomerase reverse transcriptase in chronic myeloid leukemia. Neoplasia. 2014; 16:511-528.

76. Karius T, Schnekenburger M, Ghelfi J, Walter J, Dicato M, Diederich M. Reversible epigenetic fingerprintmediated glutathione-S-transferase P1 gene silencing in human leukemia cell lines. Biochem Pharmacol. 2011; 81: 1329-1342.

77. Kumaki Y, Oda M, Okano M. QUMA: quantification tool for methylation analysis. Nucleic Acids Res. 2008; 36:W170-175 